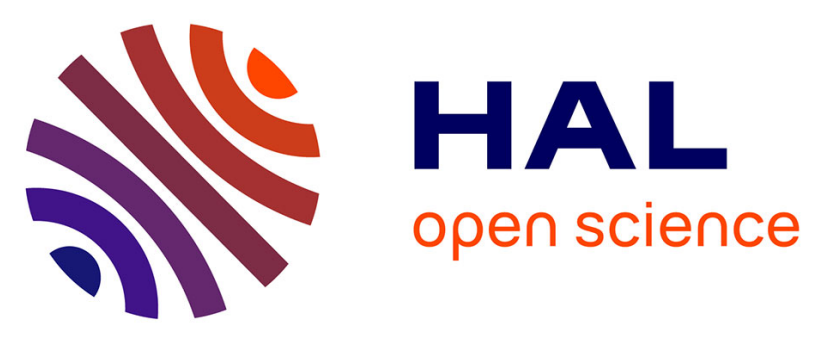

\title{
On links and tails in Italian
}

Lisa Brunetti

\section{To cite this version:}

Lisa Brunetti. On links and tails in Italian. Lingua, 2009, 119 (5), pp.756 - 781. 10.1016/j.lingua.2008.10.005 . halshs-01823529

\section{HAL Id: halshs-01823529 \\ https://shs.hal.science/halshs-01823529}

Submitted on 6 Jul 2018

HAL is a multi-disciplinary open access archive for the deposit and dissemination of scientific research documents, whether they are published or not. The documents may come from teaching and research institutions in France or abroad, or from public or private research centers.
L'archive ouverte pluridisciplinaire HAL, est destinée au dépôt et à la diffusion de documents scientifiques de niveau recherche, publiés ou non, émanant des établissements d'enseignement et de recherche français ou étrangers, des laboratoires publics ou privés. 


\author{
Lisa Brunetti, Universitat Pompeu Fabra
}

\begin{abstract}
Adopting Vallduví's partition of the background into link and tail, I provide an account for Italian data. Being links pre-focal expressions, and tails post-focal, right-dislocated expressions, I claim that links are shifting topics, while tails are discourse-given material. I show that a link is not iterated in discourse as long as the topic does not shift. If a link appears to refer to the current topic, topic shift is still visible in the interpretive effects that arise. In particular, topic shift explains why a link is sometimes contrastive. A link implies an alternative set, because a shifting topic is always sorted among alternatives. Contrast derives from the possibility to evoke alternatives and from the contextual conditions that make alternatives relevant. Since a tail never evokes alternatives, trivially there is no context where it can be contrastive. I compare Italian and other languages and observe the reduced role of intonation in the linguistic marking of Italian links. I further show that the properties of tails are shared by all post-focal material, also material not commonly analyzed as right dislocated. Independent support is given by recent syntactic accounts of post-focal background, which treat it precisely as right dislocated material.
\end{abstract}

\title{
Keywords
}

Link, tail, topic, (Clitic) Left/Right Dislocation, post-focal background, contrast

\section{Introduction}

In this paper I provide an analysis of the discourse properties of background material in Italian. Adopting Vallduví's (1992) proposal concerning the informational partition of the sentence, I assume that the Information Structure (from now on, IS) of a sentence is made of a focus and a background, and that the background is further divided in two parts: link and tail. I assume with Reinhart (1981), Vallduví (1992), and others, that links can be discourse new, while tails are only discourse old, namely, they always require an antecedent in the previous discourse. I also show that links are shifting topics, while tails never involve a topic shift. The shifting function of a link allows me to explain why a contrastive interpretation of a link, but not of a tail, arises in certain answers to a question. A link always implies the existence of an alternative set, because a new topic is always sorted among possible ones in the relevant situational context. A contrastive interpretation of the link derives from the possibility to evoke an alternative set and on the contextual conditions that make such alternatives relevant. Since a tail never evokes alternatives, trivially there cannot be any context where such alternatives are relevant. I eventually compare Italian and other languages concerning the linguistic marking of links and observe the reduced role of intonation in Italian in that respect.

In the second part of the paper I show that the properties of tails are shared by all linguistic material that is post-focal, also by material that is not commonly analyzed as right dislocated. I present a parallelism between CLRD and post-focal background in sentences with left peripheral focus (that I will call PFB). We will see that both CLRD and PFB require an antecedent and have the same possibilities to recover such an antecedent in the discourse. I also relate the presence of contrastive focus in sentences containing CLRD or PFB to the tail-like properties of both post-focal elements. 
Independent support to these findings is provided by a syntactic account of Italian leftperipheral focus given by Samek-Lodovici (2006), where the PFB is treated precisely as right dislocated material.

The paper is organized as follows. In section 2, I provide a summary of Vallduví's proposal concerning links and tails. In section 3, I describe the properties of links and tails in Italian. In section 3.1, I define their discourse status, and in section 3.2, I show that links are shifting topics. In section 3.3, I provide further evidence showing that the contrastive interpretation of a link is a result of its topic shifting property plus the particular context in which the link occurs. In section 3.3.1, a comparison is made with other languages with respect to the linguistic marking of links. In section 4, I present the similarities between CLRD and PFB and I propose that both are tails. In section 4.1, I show that post-focal material cannot be interpreted contrastively. In section 4.2, I compare the discourse properties of CLRD and PFB. In particular, in section 4.2.1, I show that both CLRD and PFB require an antecedent in the discourse; in section 4.2.2, I observe that with both CLRD and PFB, the focus of the sentence tends to be contrastive and I relate that to the tail properties of post-focal elements. In section 4.3, I eventually discuss Samek-Lodovici's (2006) syntactic account of PFB as right dislocated material, which independently supports the claim I make on pragmatic grounds. In section 5, general conclusions are drawn.

\section{Links and tails}

Vallduví (1992) takes the Information Structure (IS) to be an independent level of the grammar. He proposes that, from the point of view of IS, a sentence is partitioned into 'focus' and 'background':

(1) $\mathrm{S}=$ FOCUS + background

The focus is the informative part of the sentence, and Vallduví formally identifies it at the level of the IS by means of an operator $\Phi$. As an example of an all-focus utterance, he provides the Catalan sentence below. Its IS representation is given in (2b). Capital letters indicate focal stress:

(2) a. Ha trucat l'AMO.

has called the boss

'The Boss called'

b. $\Phi$ [ha trucat l'amo]

The background part of the sentence is further divided in two parts, called 'link' and 'tail':

(3) Background = Link + Tail

A link functions as an 'address pointer', namely it is an expression that directs "the hearer to a given address (or file card, in Reinhart's (1981) or Heim's (1983) terms) in the hearer's knowledge-store, under which the information carried by the sentence is entered" (Vallduví, 1992:59). With a simpler definition, it is "what the sentence is about' (cf. Strawson, 1964, Reinhart, 1981). A link is formally represented by Vallduví 
by the operator $\Lambda$, which stands for a quantifier-like element such that $\Lambda \mathrm{x}$ is read 'go to' and the address denoted by the link constitutes the range of $x$. In (4), a link-focus sentence is given. The link is l'amo 'the boss', and the IS representation of the sentence is given in (4b). The link is marked with boldface.

\section{(4) a. L'amo, no l'EMPRENYARIA.}

the boss not him $\mathrm{cl}$ I-would-bother

'The boss I wouldn't bother'

b. $\Lambda \mathrm{x}, \mathrm{x}=1$ 'amo [ $\Phi$ [x no l'EMPRENYARIA] $]$

Given that a link gives instructions to go to a certain address, the very presence of a link is always an indication that, in the preceding discourse, the speaker was not providing information about that address. If the address were already selected (if the information carried by the previous sentence were entered under that address) there would be no need to "go to" that address again, so no link would be uttered. This means that the presence of a link always indicates a topic shift.

A tail encompasses ground material that does not display link-like behavior. Vallduví says that a tail "is an indication that further instructions are needed to guarantee the felicitous entry of information under a specific address". In other words, a tail "specifies how the information must be entered under a specific address" (Vallduví, 1992:78). Being it part of the background, a tail must be abstracted away from the scope of $\Phi$. Vallduví represents such abstraction with the symbol $\lambda .{ }^{1}$ His example below shows a Catalan sentence containing a link-focus-tail sequence. L'amo 'the boss' is the link, l'odia 'hates it' is the focus, and el bròquil 'the broccoli' is the tail. The tail is marked with boldface italics. The IS representation of such sentence is given in (5b):

\section{(5) a. L'amo l'ODIA el bròquil.}

the boss $i_{\mathrm{cl}}$ hates the broccoli

'The boss HATES broccoli'

$$
\text { b. } \Lambda \mathrm{x}_{1}, \mathrm{x}_{1}=\text { l'amo }\left[\lambda \mathrm{x}_{2} \Phi\left[\mathrm{x}_{1} \text { l'ODIA } \mathrm{x}_{2}\right]\right] \text { (el bròquil) }
$$

I want to make clear that the terms link and tail refer to the linguistic expression that represents topical material. Following McNally (1998:163), I make a distinction between the linguistic expression and the non-linguistic notion the expression refers to, such as 'the entity the sentence is about' (or the address, in Vallduvi's terms). I refer to the non-linguistic notion with the general term topic. For instance in (4), the left dislocated direct object l'amo is a link. The referent of such expression, namely the particular person the speaker has in mind, is the topic of the sentence, what the sentence is about. A sentence like (6), which lacks a left dislocated expression (the direct object is only represented by the clitic pronoun $l$ '), may still have a topic (it may still be about the boss), although it lacks a link.

\section{(6) No l'EMPRENYARIA.}

\footnotetext{
${ }^{1}$ As he points out, the $\lambda$ symbol representing the IS of a tail has nothing to do with the same symbol used in logical semantics, representing the $\lambda$-calculus.
} 
not himel I-would-bother

'I wouldn't bother him'

\section{Links and tails in Italian}

The distribution of links and tails in Italian is very similar to that given by Vallduví for Catalan. As in Catalan, a link is a sentence initial, pre-focal expression. It occupies a (linearly) preverbal position. Typically, it is expressed by a (Clitic) Left Dislocated argument, namely an argument that is displaced in a left-peripheral, clause external position, and is resumed within the clause by a clitic pronoun. An example is the direct object $i l$ capo 'the boss' in the sentence below, corresponding exactly to the Catalan sentence in (4).

(7) Il capo, non lo DISTURBEREI.

the boss not him cl $_{\text {I-would-bother }}$

'The boss, I wouldn't bother'

A link can also be a subject. Most preverbal subjects are indeed links. ${ }^{2}$ Since there are no subject clitics in Italian, it is not evident whether subject-links occupy a left dislocated position as the other arguments do. They are clearly dislocated only when they are parted from the verb, as these examples from Benincà (1988[2001]:145) illustrate:

(8) Giorgio i giornali li compra alla stazione.

Giorgio the newspapers them $\mathrm{cl}_{\mathrm{cl}}$ buys at-the station

'The newspapers, Giorgio buys them at the station'

(9) Alice, (abbiamo deciso che), in America, ci andrà l'anno prossimo.

Alice we-have decided that in America there ${ }_{\mathrm{cl}}$ will-go the year next

'As for Alice, we decided that, to America, she will go next year'

As for subject-links that are not separated by the verb by any linguistic material, it is an open issue whether they too are dislocated - as claimed by Vallduví (1993) for Catalan, Barbosa (1997) for null subject languages, Alexiadou and Anagnostopoulou (1998) for Greek and Spanish, Manzini and Savoia (2002) and Poletto (2000) for Italian dialects or rather they occupy a canonical position (spec,IP or spec, TP, depending on the framework), as proposed for instance by Cardinaletti (1997), Benincà (2001), Rizzi (2005) for Italian, Suñer (2003) for Spanish. If it turned out that preverbal subjects that function as links are left dislocated, then Italian would display a perfect matching between the IS construction and the syntactic construction.

A tail is, typically, a Clitic Right Dislocated element (from now on, CLRD). Again, Italian resembles Catalan in this respect (cf. 5):

\section{Il capo li ODIA, $\boldsymbol{i}$ broccoli.}

\footnotetext{
${ }^{2}$ The reason for this preference is explained in Brunetti (2007, submitted). See also footnote 8 .
} 
the boss them $\mathrm{cl}_{\mathrm{cl}}$ hates the broccoli

'The boss HATES broccoli'

Italian (unlike Catalan) also accepts constructions without a resumptive clitic.

Cardinaletti (2002) shows that the two constructions have different syntactic properties. She proposes that post-focal material doubled by a clitic is a real case of right dislocation, that is, it occupies a position outside the clause, while non-doubled material occupies a position inside the clause. She calls the latter marginalisation. As Frascarelli (2000) observes by looking at examples from speech corpora, marginalised material is extremely rare and is used in a restricted number of contexts. Both Frascarelli and Cardinaletti notice that marginalisation is used when the focus has a contrastive/corrective interpretation. In Brunetti (2004), an explanation of this preference is given, based on the information status of the antecedent of the marginalised element._When the antecedent is focused, a marginalised element is preferred. When the antecedent is background material, either a clitic alone or a CLRD are preferred. In both cases, however, the post-focal element has an antecedent in the discourse, so the idea proposed by Frascarelli that the marginalised element is focused does not seem to be correct. ${ }^{3}$ Indeed, in contexts where a marginalisation is possible, the corresponding right dislocation is possible as well. Moreover, both marginalised and right dislocated material are deaccented elements that follow the focal accent. I am therefore inclined to say that a marginalised element is a tail. In this paper, however, I will only focus on right dislocated elements.

As for a subject with the function of tail, since Italian allows different positions for subjects in the clause, its position is a post-focal one, as in the example below.

\section{Le verdure proprio non le VUOLE, il capo.}

the vegetables really not them $\mathrm{cl}_{\mathrm{cl}}$ he-wants the boss

'He really doesn't want vegetables, the boss'

The same discussion regarding subject-links can be made for subject-tails: it is an open issue whether they are in situ (as proposed for instance by Kayne, 1994 and Cecchetto, 1999), or right dislocated (as proposed e.g. by Vallduví, 1992, Cardinaletti, 2002, Belletti, 2004), or both (as in Cardinaletti's account mentioned above). ${ }^{4}$ In this paper we will see that from a pragmatic point of view, post-focal subjects (and post-focal material in general) have the same function as right dislocated material. Thus, an analysis of post-focal subjects as right dislocated would confirm the matching between syntax and IS in Italian. ${ }^{5}$

In Section 4 we will eventually see that tail-like properties are shared by background material that follows a left peripheral focus. Again, if this kind of post-focal material was analyzed as right dislocated, the matching between syntax and IS would be

\footnotetext{
${ }^{3}$ For syntactic arguments against Frascarelli's proposal, see Brunetti (2004).

${ }^{4}$ Even focused elements can occupy a pre-verbal and a post-verbal position in the clause. However, focused elements bear nuclear stress, while CLLD and CLRD elements do not. Furthermore, focus positions are syntactically distinguishable from CLLD and CLRD for they lack of resumptive clitic inside the clause (cf. Rizzi, 1997). Given that subjects always lack resumptive clitics, focused and non-focused subjects are only distinguishable by their prosody.

${ }^{5}$ Although we would still have to accept the possibility that a restricted set of tails, that is marginalised expressions, are not dislocated.
} 
supported. We will see that a syntactic analysis of this kind has indeed been proposed in the literature. Note, however, that the main concern of this paper is to discuss the discourse properties of Italian background, and is not meant to provide a syntactic analysis of it. Therefore, I will only suggest a possible correspondence between certain syntactic constructions and certain pragmatic constructions, without providing syntactic evidence for it.

\subsection{Discourse status}

I call an expression 'discourse old' if its referent has already been mentioned in the previous discourse or it is somehow recoverable from it, or at least it is recoverable from the extra-linguistic, situational context. An expression is 'discourse new' if it has not been mentioned before nor is recoverable from the linguistic or situational context. ${ }^{6}$

With Reinhart (1981), Vallduví (1992), Benincà (1988[2001]:145), and others (see more recently, Endriss, 2006), I claim that a link does not have to be discourse old, namely its referent does not need to be present in the previous discourse or in the situational context. The sentences below show that. These sentences can be uttered at the beginning of a conversation, so no previous mention of Dante in (12), the speaker's friend in (13), or the speaker's brother in (14) was made in the discourse. The expression Sai? 'Did you know?' indicates that the sentence begins a conversation, in an 'out of the blue' fashion. Notice further that un mio amico 'a friend of mine' is an indefinite expression, which typically signals novelty of a referent in the discourse. Indefinite expressions can be links when interpreted as specific (as in 13) or as generic. ${ }^{7}$

(12) Sai? Dante lo hanno bocciato all'esame di chimica.

you-know, Dante him $\mathrm{cl}$ they-have failed at-the exam of chemistry

'Did you know? Dante failed at the chemistry exam'

(13) Sai? Un mio amico ha vinto la lotteria.

you-know a my friend has won the lottery

'Did you know? a friend of mine won the lottery'

Sai? A mio fratello (gli) hanno rubato la moto.

you-know to my brother to-him $\mathrm{cl}_{\mathrm{cl}}$ they-have stolen the motorbike

'Did you know? My brother got his motorbike stolen'

Benincà (1988[2001]) says that a CLLD, even when discourse new, must be generally present in the mind of the listener. This is perhaps too strong of a statement.

\footnotetext{
${ }^{6}$ Among the several studies that discuss what means for an expression to be 'old' (or 'given') and 'new', see Chafe (1976), Prince (1992), Lambrecht (1994). For an interesting survey of the literature, see Vallduví (1992:20-26). For a formal characterization of the notion of givenness, see Schwarzschild (1999).

7 The indefinite can also be a left dislocated object, as the example below shows:

(i) Non sai cos'e' successo! A un mio amico (gli) hanno dato il Nobel per la Fisica! you-not know what is happened to a my friend to-him $\mathrm{cl}_{\mathrm{cl}}$ they-have given the Nobel for the Physics 'You don't know what happened! A friend of mine was given the Nobel Prize for physics!' Cf. Ward and Prince (1991), where several examples of indefinite LDs in English are discussed. See also Endriss (2006) for an analysis of indefinites and other quantifiers in LD-ed position in German.
} 
The listener must know who Dante is in (12), but in (13) and (14) she does not need to know who the speaker's friend is or that the speaker has a brother. If we adopt Vallduví's definition of link as an address pointer, it is part of its very definition that a link must somehow be anchored to the common ground. Such anchoring, however, can be extremely weak. It is sufficient for the link to be somehow related to either the speaker or the hearer, or to the situation in which the conversation takes place (time and space), or else to the common knowledge that the interlocutors assume to share. In (13) and (14), the anchoring is done by means of the possessive mio 'my'. The fact that the link refers to the speaker's friend or brother is sufficient for the expression to function as a suitable address under which the information is stored. The hearer can in fact easily accommodate that the speaker has a friend in (13) or that the speaker has a brother in $(14) .^{8}$

Tails behave differently. They do not simply have to be anchored to the discourse, but must be anaphoric, namely, they always need that an antecedent be present in the discourse or in the situational context ${ }^{9}$. This is shown by the fact that, if we shift Dante, un mio amico and a mio fratello in (12)-(14) from a left to a right dislocated position, the sentences result less felicitous, as illustrated below:

?? Sai? $\quad$ Lo hanno bocciato all'esame di chimica, Dante.

you-know him $_{\mathrm{cl}}$ they-have failed at-the exam of chemistry Dante

?? Sai? Ha vinto la lotteria, un mio amico.

you-know has won the lottery a my friend

?? Sai? (Gli) hanno rubato la moto, a mio fratello.

you-know to-him ${ }_{\mathrm{cl}}$ they-have stolen the motorbike to my brother

Among nine native speakers I consulted, five completely reject (15), and three find it rather bad. The informant that accepts it still finds (12) better. As for (16), five informants out of nine reject it, and four find it odd. Finally, (17) is completely rejected by three informants, it is found rather bad by four, and it is accepted by two (one finds it worse than 14, the other does not see any difference between the two). Sentence (15) would be acceptable if the interlocutors had been talking about Dante until then, and (17) if the interlocutors had been talking about the speaker's brother. In these cases, Sai? would indicate that the speaker wants to tell a new story, unrelated to the previous conversation. The story, though, is still about Dante in (15) or the speaker's brother in (17), and this allows the presence of the tail. ${ }^{10}$ The tail in (16) contains an indefinite, so the sentence would not be acceptable in a completely out of the blue context, as it is

\footnotetext{
${ }^{8}$ Note that in the examples where the link is not a subject, the subject is an arbitrary plural. Brunetti (2007, submitted) provides an explanation for that (cf. also Salvi, 1988[2001]). Most verbs select a subject that has semantic/thematic characteristics that make it a 'good' link (Reinhart, 1981, van Oosten, 1986, a.m.o.). When the subject has such characteristics, and the sentence is uttered out of the blue, the speaker tends to choose it as link. However, if the subject is arbitrary, it lacks referential status, and therefore it is inadequate to function as link (cf. Murcia-Serra, 2003). The speaker then may choose a different argument in link position. See Brunetti (2007, submitted) for other cases of subjects that are not 'good links'. See also the discussion below in section 3.3.

${ }^{9} \mathrm{Cf}$. studies on the discourse status of right dislocation in English (e.g. Ziv and Grosz, 1994), or Catalan (e.g. Mayol, 2002).

${ }^{10}$ In other words, discourse segmentation and discourse structure play a role in the acceptability of background material.
} 
unlikely that the interlocutors talked about a specific friend of the speaker's and then the speaker uttered (16) using an indefinite to refer to that same friend.

\subsection{Links as shifting topics}

Benincà (1988[2001]:162) presents another difference between CLLD and CLRD. Consider the minimal pair below:

a. * Il dolce, lo porto io; lo porti tu, il vino.

the cake $i_{\mathrm{cl}}$ bring $\mathrm{I} \mathrm{it}_{\mathrm{cl}}$ bring you the wine

b. Il dolce, lo porto io; il vino, lo porti tu.

the cake $\mathrm{it}_{\mathrm{cl}}$ bring $\mathrm{I}$ the wine $\mathrm{it}_{\mathrm{cl}}$ bring you

'I'll bring the cake, you'll bring the wine'

The ungrammaticality of (18a) is due to the presence of a CLRD in the second conjunct, as it is confirmed by the grammaticality of (18b). The explanation Benincà gives for this difference is that a CLRD cannot 'impose' a new topic in the discourse. ${ }^{11}$ In (18a), the topic is the cake, and therefore the wine would constitute a new topic, but in order for the wine to constitute a new topic, it has to be expressed by a CLLD.

In this paper, I claim that a CLLD, as the object il dolce, is a link. According to Vallduví's definition of link, a link represents a shifting topic. Therefore, my claim is not just that a CLLD can represent a shifting topic, as Benincà observes, but more strongly, that it represents it by default, for the very fact of being a link (cf. also Brunetti, 2006). In this section and in the subsequent one, I will provide empirical support for this claim. In the examples presented in this section, topic shift occurs within the same speech turn; in the examples in the following section, topic shift will be observed in correspondence with a change of turn in the dialogue.

The first set of examples shows that once the topic is introduced in the discourse under the form of a link, no further realizations of that topic as a link appear in subsequent sentences, as long as the topic remains the same. The topic can only be realized again as a link if the topic 'continuum' is interrupted by the introduction of a different topic. ${ }^{12}$ Consider the chunk of discourse in (19), taken from the LIP corpus of

\footnotetext{
${ }^{11}$ Benincà calls a new topic tema 'theme'.

${ }^{12}$ The relation between presence or absence of an expression and topic continuity has already been observed by the literature on subject omission in null subject languages. Samek-Lodovici (1996) proposes that null subjects are licensed by topic antecedents. Within the Centering Theory framework (Grosz et al., 1995), similar licensing conditions have been proposed for null subjects in various languages (see e.g. Walker et al., 1994 for Japanese, Turan, 1995 for Turkish, Di Eugenio, 1990, 1998 for Italian). In this paper, I generalize this observation to all arguments in sentence initial position. The only difference between a subject and a non-subject is that when the latter is omitted, a clitic is present. This is a morphological difference due to the fact that there are no null arguments other than the subject in Italian. Consider for instance the corpus example below.

(i) ... e il cane casca dalla finestra, col barattolo infilato nella testa e gli si rompe il barattolo... and the dog falls from-the window with-the bottle wedged in-the head and to-him $\mathrm{cl}_{\mathrm{cl}} \mathrm{RFL}_{\mathrm{cl}}$ breaks the bottle

' $\ldots$ and the dog falls out of the window with the bottle wedged into his head, and the bottle breaks...' The topic of the first sentence is the dog, referred to by a link. In the subsequent sentence, the topic is still the dog, so the sentence has no link: the object referring to the dog is hence indicated by the sole dative clitic gli.
} 
spoken Italian (De Mauro et al., 1993) ${ }^{13}$. A student is telling a professor about the content of some documents.

(19) in essi vengono trattati numerose conferenze come ho detto prima

in them are treated several conferences as I-have said before

riguardanti molti paesi del mondo e Ø vengono anche riportati eh talvolta

regarding many countries of-the world and are also reported hum sometimes

riportati i punti principali trattati; $\varnothing$ viene trattato inoltre uno dei

reported the main points treated is treated furthermore one of-the

problemi piu' attuali e gravi ...

problems more up-to-date and serious ...

'They talk about several conferences concerning many countries in the world and they also report the main points treated there; they further deal with one of the most up to date and serious problems...'

The sentence initial expression in essi 'in them', referring to the documents the student read, introduces the topic of this chunk of discourse. The expression is then omitted (as the $\varnothing$ symbol indicates) in subsequent sentences. ${ }^{14}$ In (20), the topic is realized again as a link after the topic 'continuum' has been interrupted by the insertion of a different topic. The example is taken from a story told by an Italian native-speaker by looking at a series of pictures. The story is one of Mercer Mayer's wordless books telling the adventures of a boy and his frog friend (see Berman and Slobin, 1994, Strömqvist and Verhoven, 2004). ${ }^{15}$

a. dunque il bambino si prepara

per andare a...

so the boy is-getting-ready to go to...

b. Ø è davanti allo specchio

is in-front of-the mirror

c. e $\varnothing$ si prepara, $\quad \varnothing$ si mette la cravatta per andare al ristorante (...) and $\mathrm{RFL}_{\mathrm{cl}}$ is-getting-ready $\mathrm{RFL}_{\mathrm{cl}}$ puts-on the tie to go to-the restaurant

d. e i suoi amici lo guardano tristi perché sanno che non andranno con lui

\footnotetext{
${ }^{13}$ The dialogues of the LIP corpus reported in this paper are either phone calls or face-to-face spontaneous conversations among speakers of the central variety of Italian (precisely, the varieties of Florence and Rome).

${ }^{14}$ A similar behavior is observed by Butt and King (1997) for Hindi, which is a language that allows null arguments. Butt and King provide similar data as mine and conclude that in Hindi "continuing topics, i.e., entities that are the topic of the current utterance and of the previous utterance, can be dropped and in general do not occur overtly" (Butt \& King, 1997:14). Cf. also Lambrecht and Michaelis (1998:500) for English.

${ }^{15}$ These data are collected by the author within the project Nocando, Construcciones no-canónical en el discurso oral: estudio transversal y compartivo, Universitat Pompeu Fabra, Barcelona. The project was funded by the Spanish Secretaria de Estado de Universidades e Investigación del Ministerio de Educación y Ciencia, n. I+D HUM2004-04463.
} 
and the his friends $\operatorname{him}_{\mathrm{cl}}$ watch sad because they-know that not will-go with him
e. Allora poi il bambino saluta
il cane e la tartaruga $(. .$.

so then the boy greets the dog and the turtle (...)

'So the boy is getting ready to go to... he stands in front of the mirror, getting ready, putting on his tie to go to the restaurant (...), and his friends are watching him with sad faces because they know they won't go with him. Then the boy says good-bye to the dog and the turtle (...)'

The link il bambino 'the boy' introduces a topic, which remains the same in subsequent sentences ( $\mathrm{b}$ and $\mathrm{c}$ ). Then $i$ suoi amici 'his friends' is uttered in sentence initial position (d), so it introduces a new topic, and this causes an interruption of the topic continuum. In e, il bambino is uttered again in order to reintroduce the previous topic, after the interruption in $\mathrm{d} .{ }^{16}$ The realization of $i l$ bambino in e shows that, in order to have a link, the link has to represent a topic shift. ${ }^{17}$

A continuous topic can be realized as a tail. An example of this possibility is given by the following excerpt of the LIP corpus, selected by Frascarelli (2000).

\section{(21) Non è questione che il tempo non te l'ho DATO; io te l' ho DATO il tempo}

not is question that the time not to-you $\mathrm{cl}_{\mathrm{cl}} \mathrm{it}_{\mathrm{cl}} \mathrm{I}$-have given $\mathrm{I}$ to-you $\mathrm{u}_{\mathrm{cl}} \mathrm{it}_{\mathrm{cl}}$ have given the time

'The point is not that I didn't give you time. I DID give you time.'

Il tempo 'the time' is uttered as a CLLD in the first sentence, where it introduces the topic (it is a link). In the second sentence it is uttered again, but as a CLRD, therefore it functions as a tail. Another example is the one below, which I selected from the LIP corpus:

A: ah ho capito, ma $\mathbf{X Y Z} \mathbf{Z}^{18}$ che cosa vorrebbe? altri sconti... uh I-have understood but XYZ what would-want other discounts...

'Uh, I understand, but XYZ, what does he want? Other discounts..'

B: no, niente, eh, trovare una soluzione

no nothing eh find a solution

'No, nothing, just find a solution'

A': ah va be', la soluzione gliela troviamo, naturalmente gli taglieremo dei

\footnotetext{
${ }^{16}$ Things may be complicated by the fact that there isn't necessarily one single topic for each chunk of conversation. See the discussion on 'successive queries' in Ginzburg (forthcoming). I will leave this issue aside here.

${ }^{17}$ The situation is again similar in Hindi. Butt and King (1997) say that in Hindi "arguments which function as a topic within their clause, but which simultaneously indicate a change (switch) in topic from the preceding utterance, cannot be realized as null" (Butt and King, 1997:13). As I said above, my claim about Italian is stronger, namely not only it is the case that a shifting topic cannot be null, but also that an overtly realized link always represents a shifting topic.

${ }^{18} \mathrm{XYZ}$ stands for the person's real name, which has been omitted in the transcription.
} 
margini, $\boldsymbol{a} X Y Z$

uh ok the solution for-him ${ }_{\mathrm{cl}}-\mathrm{it}_{\mathrm{cl}}$ we-find of-course to-him $\mathrm{cl}_{\mathrm{l}}$ we-will-cut some margins to XYZ to XYZ'

'Uh that's ok, we'll find a solution for him; of course we'll cut some margins,

In $\mathrm{A}, \mathrm{XYZ}$ is introduced as a topic. In $\mathrm{B}, \mathrm{XYZ}$ is still the topic (we are still talking about what $X Y Z$ wants) and the expression is omitted. In $A^{\prime}$, we are still talking about $\mathrm{XYZ}$, which is uttered as a CLRD, that is as a tail.

In some discourse contexts, a sequence of links can be found that refers to the same topic, contrary to what we have seen so far. An example is (23), suggested to me by an anonymous reviewer. The sentences have to be imagined as uttered by a die-hard environmentalist at some protest rally:

(23) a. Il riscaldamento globale non lo nega più nessuno. the warming global not $\mathrm{it}_{\mathrm{cl}}$ deny anymore nobody

b. Il riscaldamento globale lo riconoscono ormai anche gli Stati Uniti e la Cina. the warming global $\mathrm{it}_{\mathrm{cl}}$ recognize even the U.S.A. and the China

c. Il riscaldamento globale deve divenire una priorità del governo! the warming global must become a priority of-the government "Global warming cannot be denied by anybody any more; global warming is recognized even by U.S.A. and China; global warming has to become a priority of our administration!"

Clearly, il riscaldamento globale represents the topic of all three sentences. Since a link represents a shifting topic, we do not expect the same link to be present in b and c. But the example does not contradict my hypothesis. In fact, (23) has a special rhetorical emphasis, which can be explained precisely by the unexpected iteration of the same link. The re-introduction of the same topic by repeating the link emphasizes the importance of what the speaker is talking about, or underlines the fact that precisely such a topic, and not other possible ones in the context, is the one about which that particular piece of information has to be provided. In the reviewer's words, "the hearer expects a shift, but in fact the shift is back to the same topic, which gets emphasized in the hearers' mind by the unexpected hence surprising coincidence". ${ }^{19}$

That the rhetorical effect is given by the shifting function of the link and not just by the repetition of il riscaldamento globale is proved by the example below, identical to (23) except for the position of il riscaldamento globale, which is a tail. With such a change in word order, the rhetorical effect disappears: the discourse simply sounds odd, and the dislocated expression redundant.

a. Non lo nega più NESSUNO, il riscaldamento globale.

not $\mathrm{it}_{\mathrm{cl}}$ deny anymore nobody the warming global

\footnotetext{
${ }^{19} \mathrm{I}$ thank the reviewer for this piece of data and his/her observations.
} 


\section{b. Lo riconoscono anche gli Stati UNITI, il riscaldamento globale.}

$\mathrm{it}_{\mathrm{cl}}$ recognize even the U.S.A. the warming global

c. Deve divenire una priorità del GOVERNO, il riscaldamento globale!

must become a priority of-the government the warming global

In fact, no shift is expected by the hearer in (24), since a tail simply recovers a referent from previous discourse. Therefore, no rhetorical effect can be produced by the fact that "the shift is back to the same topic". If any rhetorical effect arises in (24), it will be different from that in (23): it will be the effect of iterating an expression whose referent is perfectly recoverable from the context.

In the following section we will see another context where the link is unexpected, because it seems to refer to a continuous topic. The example is a question-answer pair, and the unexpected link is in the answer. We will see that even in this case, the function of the link remains that of shifting the topic, and again that function is the cause of a particular interpretive effect.

\subsection{Links as shifting topics and contrast}

An important difference between link and tail is that a link can be interpreted contrastively, while a tail cannot. Such a difference is particularly evident in an answer to a wh-question. Consider the example below:

$$
\begin{aligned}
& \text { A: A Dante, che cosa (gli) regalerai? } \\
& \text { to Dante what to-him }{ }_{\mathrm{cl}} \text { will-you give } \\
& \text { 'What will you give to Dante (as a present)?' } \\
& \text { B1: (Gli) regalerò un LIBRO, a Dante. } \\
& \text { to-him }{ }_{\mathrm{cl}} \text { I-will-give a book to Dante } \\
& \text { 'I'll give Dante a book' }
\end{aligned}
$$

B2: A Dante (gli) regalerò un LIBRO.

to Dante to-him $\mathrm{cl}$ I-will-give a book

'To Dante I'll give a book'

The question can be answered by both B1 and B2. However, there are some differences in acceptability and interpretation. As for acceptability, B1 can be felt as a little redundant, and the reader is tempted not to pronounce Dante at the end. B2, on the contrary, sounds fine in this respect. As for the interpretation, however, B1 is a complete answer to the question; with B2, instead, one expects to know about other friends/relatives to whom the speaker will give (or not give) presents. For instance, the sentence could have the follow-up:

(25)' B2: A Dante (gli) regalerò un libro; a Ugo e Leo, invece, regalerò dei cd.

to Dante to-him ${ }_{\mathrm{cl}}$ I-will-give a book to Ugo and Leo instead I-will-give some CDs

'As for Dante, I'll give him a book; but as for Ugo and Leo, I'll give them CDs' 
This difference has also been noted for Catalan (see Vallduví,1995, Villalba,1998), and for Spanish by Arregi (2003). My example in (25) in fact mirrors Arregi's example, reported below:

Q: ¿Qué le diste a Juan?

what to-him cl $_{\text {you-gave to Juan }}$

'What did you give to Juan?'

A: Le di un libro (a Juan).

to-him $\mathrm{cl}$ I-gave a book to Juan

'I gave a BOOK to Juan'

A': A Juan, le di un libro.

to Juan to-him ${ }_{\mathrm{cl}}$ I-gave a book

'To Juan I gave a BOOK'

As Arregi points out, "while answer A is simply a complete answer to the question, answer A', which involves CLLD of Juan, in addition, presupposes that there are other people the speaker gave things to" (Arregi, 2003:33). Arregi explains this difference by proposing that the semantics of a CLLD is that of Büring's (1997) 'S-topic'.

Büring (1997) bases his analysis on English and German data. An S-topic is an expression that bears a special accent, called 'B-accent' in English (see Bolinger, 1965, Jackendoff, 1972) and 'T-accent' in German. ${ }^{20}$ The B-accent is a fall-rise tone, that Pierrehumbert (1980) represents as $\mathrm{H}^{*} \mathrm{LH} \%$, namely a high tone on the most prominent syllable followed by a low tone, and then a phrase final rise. As for the T-accent, Büring describes it as a low tone on the most prominent syllable, followed by a high tone $(\mathrm{L} * \mathrm{H})$. Büring semantically analyzes an S-topic as an alternative set of propositions, in a way analogous to Rooth's (1992) analysis of focus. Rooth proposes that sentences have a 'focus semantic value' defined as "a set of propositions obtainable from the ordinary semantic value by making a substitution in the position corresponding to the focused phrase" (Rooth, 1992:76). For instance, the focus semantic value of a sentence like (27a) is a set of propositions of the form I gave $x$ to John, like those in (27b).
a. I gave a BOOK to John.
b. I gave a book to John, I gave a CD to John, I gave a watch to John, etc.

The meaning of a sentence with an S-topic, according to Büring (1997), is a set of sets of propositions (or put it otherwise, a set of questions). For instance, the sentence in (28B), where the female pop stars is an S-topic (it bears a B accent), has the representation in (29), where the subsets contained in the larger set are the alternatives created by the focus, and the more external brackets represent the alternative set created by the topic:

(28) A: What did the pop stars wear?

B: The female pop stars wore CAFTANS.

\footnotetext{
${ }^{20}$ The name 'T-accent' was given by Büring to the German accent for analogy with the English one.
} 
the female pop stars wore white dresses

the female pop stars wore tuxedos... $\}$,

$\{$ the male pop stars wore caftans

the male pop stars wore white dresses

the male pop stars wore tuxedos... $\}$... .

Assuming this analysis, Arregi says that in (26A') "the speaker presupposes that Juan belongs to a set of individuals $x$ for whom the question What did you give $x$ ? is relevant" (Arregi, 2003:3). Therefore, the alternative set interpretation of a CLLD comes from its very semantics.

Arregi's claim is challenged in Italian by a sentence like (14), repeated below:

\section{(14) Sai? A mio fratello (gli)}

hanno rubato la moto.

you-know to my brother to-him $\mathrm{cl}_{\mathrm{cl}}$ they-have stolen the motorbike

'Did you know? My brother got his motorbike stolen'

Sai? 'You know?' indicates that the sentence is uttered at the beginning of a conversation. No alternative set is evoked by the CLLD. The hearer does not infer that the speaker's brother is contrasted with other individuals. Indeed, the presence of the CLLD has rather to do with the fact that the indirect object is the best argument to function as topic in this sentence, given the referential weakness of the subject (see footnote 8). Therefore, given the non-contrastive interpretation of this sentence, we cannot say that contrast results from the semantics of the CLLD: in order to express contrast, the CLLD must occur in a context like (25).

Why is it so? I argue that a contrastive interpretation can only be explained if we assume that the CLLD, which is a link, represents a shifting topic. Consider (25A). The question is about Dante, so Dante represents the topic of the question. Given that an answer must be congruent with its question, one expects the answer to have the same topic. If we assume that the CLLD represents a shifting topic, its presence is unexpected, as the topic should be continuous. But it is precisely the unexpectedness of the CLLD that explains its contrastive interpretation. By introducing the topic again as if it were shifting, the speaker evokes again the possible alternatives to it, so the listener infers that the speaker intends to contrast the topic with those alternatives. In other words, the presence of the link indicates that the speaker does not simply want to answer the question, but that she also wants to add a contrastive interpretation. We can say that the contrastive interpretation legitimates the unexpected iteration of the link in the answer. In (14), on the contrary, the presence of the link does not have to be legitimated by contrast. The sentence is uttered in an 'out of the blue' context, so the link cannot indicate but the introduction of a new topic.

Further evidence of my claim is provided by the example below, which is very similar to (25) but is uttered in a slightly different scenario. The birthday of Francesca's little nephew, Luca, is approaching; a friend of Francesca's asks her what she is going to give Luca as a present.

Friend: Allora hai deciso? Che cosa gli regali a Luca per il compleanno? 
'So, are you decided? What are you giving Luca for his birthday?'

Francesca: (\# A Luca) gli regalo una scatola di costruzioni.

\section{to Luca to-him ${ }_{\mathrm{cl}}$ I-give a box of building-blocks}

14 native speakers were consulted on this example. Among them, only one accepts the answer with the CLLD. The other 13 strongly reject it. Many of them specify that they would accept it only in case the context could admit the existence of some alternatives to Luca. The context of this sentence, however, strongly disfavors that interpretation: Francesca and her friend are talking about Luca's birthday, so no other people are expected to receive a present, and Francesca is only expected to answer about what she will give to Luca. Consequently, no contrastive interpretation is given by the informants, and only a further reflection on the example leads them to suggest it. In (25), on the contrary, the reason of the present is not specified, so the listener can imagine a situation - say, Christmas - in which the speaker is planning to give presents to other people than Dante.

What about the answer with a tail? As the interpretation of (25B1) shows, and as further examples in the following sections will illustrate, a tail can never have a contrastive interpretation. In any case, such an interpretation is not necessary, as a tail does not indicate a topic shift. Therefore, Dante simply recalls the topic in the question, and the answer is a complete one. This also explains why the answer may sound a little redundant. It is easy to recover the antecedent for a tail if the antecedent is in the preceding question, given that we expect the answer and the question to be congruent (see also discussion about ex. 44 in section 4.2 .1 below). It is noted by a reviewer that an answer like (25B1) is fine also if it is followed by a sentence that mentions alternative individuals to Dante:

(25)' A: A Dante che cosa regalerai?

to Dante what will-you give

'What will you give to Dante (as a present)?'

B1: (Gli) regalerò un libro, a Dante; a Ugo e Leo invece (gli) regalerò dei cd.

to-him $_{\mathrm{cl}}$ I-will-give a book to Dante, to Ugo and Leo instead to-them ${ }_{\mathrm{cl}}$ I-will-give some CDs

'I'll give a BOOK to Dante; as for Ugo and Leo, I'll give them CDs'

The acceptability of (25' 'B1) does not challenge my claim. When the topic is a link, it makes the listener infer that the possible alternatives to the topic are relevant, even without any explicit mention of such alternatives (cf. 25B2). If the topic is a tail, such an implicature is not present. Indeed the sentence in (25B1), by itself, is not able to evoke alternatives. That does not prevent the speaker to talk about other individuals in a successive sentence, and therefore introduce other members of a set that can include Dante.

Summarizing, since a link represents a topic shift, it always implies the existence of an alternative set, as a new topic is sorted among a set of possible ones in the relevant situational context. The property of evoking an alternative set distinguishes a link from a tail. Since a tail does not sort any new topic, it does not introduce any alternative set either. The contrastive interpretation of a link but not of a tail comes as a consequence: 
the possibility to evoke an alternative set is a necessary condition to get a contrastive interpretation.

The possibility to evoke an alternative set is though not a sufficient condition for contrast: a contrastive interpretation of a link depends on the context in which the link occurs. Consequently, the alternatives to the link only become apparent in certain contexts. When the context does not force a contrastive interpretation, as in (14), the fact that the link is selected among alternatives is irrelevant and is not considered by the listener. When the context forces a contrastive interpretation, like in (25), the alternatives to the link become instead relevant, because the link is contrasted with them: the piece of information provided about the link is different from that given or meant to be given about the other members of the set. In effect, if a contrastive interpretation of a link is given, the focus has a contrastive 'flavor' as well. For instance, if one utters (25B2), it is natural to think that the speaker will most probably give a different present to someone else. ${ }^{21}$

Going back to Arregi's proposal, I therefore agree with him that a CLLD evokes an alternative set. However, while Arregi adopts Büring's (1997) account to characterize the semantics of the CLLD, I derive the alternative-set interpretation from Vallduvi's (pragmatic, not semantic) definition of link, namely from the fact that a link is a shifting topic. ${ }^{22}$ The conclusions are eventually the same, but my perspective has the advantage to provide a unified account of pre-focal topic expressions, either contrasting or not. A link is an address pointer, an indicator of a topic shift. The fact that a link implies the existence of alternatives comes as a consequence: selecting a topic (or an address, in Vallduví's terms) from the hearer's knowledge store always implies to choose among potentially different alternatives that may be relevant in the context. But the relevance of the alternatives varies according to the context: in (14), the alternatives are not relevant, so they are not evoked; in (25B2), the only reason to have a link is that the speaker wants to contrast the current topic with its alternatives, so the alternatives are in this case relevant, and they are therefore inferred by the listener.

\subsubsection{A crosslinguistic comparison and the linguistic marking of links}

Recall that Büring's (1997) S-topic is marked with an accent in English and German. In Büring's account, the accent correlates with the alternative set interpretation of the topic. Arregi (2003) assumes Büring's semantic analysis to explain the interpretation of a CLLD, so for him, it is the syntactic position that determines such interpretation in Spanish. We have seen above that I basically reach the same conclusions for Italian, although I do not assume that the CLLD has a particular semantics, but rather that it has a particular discourse function (that of a link).

It is tempting to transfer my analysis of Italian links to English and German links, namely to say that even in these languages what the accent indicates is the link, and the corresponding non-accented expressions are tails. Indeed, this idea has been proposed (or assumed) by various scholars: see for instance Vallduví and Enghdal (1996), Vallduví and Vilkuna (1998), McNally (1998), Lee (1999), Molnar (2002), etc. The idea is that while in Italian (and other Romance languages) there is a distinction between two positions, in English and German the distinction is between an expression bearing an accent, functioning as a link, and an expression not bearing an accent,

\footnotetext{
${ }^{21}$ The formulation of this proposal is strongly indebted to an anonymous reviewer's comments and suggestions, and to a fruitful discussion with Enric Vallduví. I thank them both.

${ }^{22}$ My proposal is closer to what Büring proposes in a later paper: see Büring (2003).
} 
functioning as a tail. So the contrast between (25B1) and (25B2) would correspond in English to the contrast between John in B1 and B2 below, one bearing a B-accent and the other not. In B2, John, bearing a B-accent, would be interpreted contrastively, for the same reasons alleged for (25B2).
A: What did John eat?
B1: John ate a burrito.
B2: John ate a burrito.

$$
\begin{aligned}
& (\boldsymbol{J o h n}=\text { tail }) \\
& (\mathbf{J o h n}=\text { link })
\end{aligned}
$$

A deeper analysis of the differences between English and Italian would be necessary to verify this hypothesis, in particular with respect to the intonation of Italian links. I will leave it to future research. ${ }^{23}$ Here I will simply report some examples that seem to support this idea. Consider the Italian data below.

\section{a. I gatti non mangiavano dalla mattina.}

'The cats had not eaten since the morning'

b. I piccoli li avevo chiusi fuori per sbaglio.

the little them $\mathrm{cl}_{\mathrm{I}}$-had closed out for mistake

'The young ones, I had closed outside by mistake'

b'. Li avevo chiusi fuori per sbaglio, i piccoli.

them $_{\mathrm{cl}} \mathrm{I}$-had closed out for mistake the little-ones

'I had closed the poor things outside by mistake'

The sentence in (32a) can be followed by both $b$ and b'. If it is followed by $b$, all ten native speakers I consulted interpret $i$ piccoli 'the little ones' as referring to a subset of cats - the subset of the young ones - and they expect the sentence to be followed by another one where additional information about the older cats is given. On the contrary, if (32a) is followed by b', all ten informants interpret $i$ piccoli as an expression of affection referring to the whole set of cats. ${ }^{24}$ In other words, in $b$ an alternative set

\footnotetext{
${ }^{23}$ Some scholars have in fact started to pay attention to the pragmatics-prosody interface concerning topic expressions in Italian. In particular, Frascarelli and Hinterhoelzl (2007) propose three different intonational contours for three different kinds of topics: a $\mathrm{L}^{*}+\mathrm{H}$ contour for a shifting topic, a $\mathrm{H}^{*}$ contour for a contrastive topic, and a $\mathrm{L}^{*}$ contour for a continuous topic. Their results, however, cannot be conclusive. Since these authors use a spontaneous speech corpus, the words used to show the three accents are different in form and length, so it is hard to compare the three contours. Furthermore, no clear example of the prosody of a pre-focal continuous topic is given: in the sole example they provide, the topic is preceded by another topic, and it could be the case that the pitch on the first topic affects the prosody of the following one. Finally, it is sometimes hard in their examples to recognize - and to have evidence from the given context - of the real pragmatic intentions of the speaker, namely if s/he wanted to utter the topic in contrast with another one, or just shift it without any intention to contrast it, or just to recover it from previous discourse without producing any shift. Since they often use prosody to confirm the speaker's intentions, their argument is circular. For all these factors, I think further data are needed, in particular specific tests should be conducted that focus exactly on the question-answer pairs discussed in this paper. For a first step in this direction, see D'Imperio et al. (2008).

${ }^{24}$ Two informants can also give partial reading to (32b'). This is also the interpretation of an anonymous reviewer. S/he observes that with the partial reading, both the CLLD and the CLRD seem to have a different intonation. The reviewer's judgment on the prosody of the CLRD is unexpected, since a CLRD has always been analyzed as de-accented material in the literature, or at most, as displaying a reduced,
} 
interpretation is given. In b', an alternative set interpretation is not (or very hardly) available, plus, a tail needs an antecedent, so a natural interpretation is one where $i$ piccoli refers to the whole set of cats. With such a referent, $i$ piccoli is then interpreted as an epithet of affection.

This example shows that the natural interpretation of a sentence initial, left dislocated (background) expression in Italian is that of a link. Note that it is rather unexpected that the speaker in b only talks about the subset of young cats. The sentence in $b$ is interpreted as an explanation of why the cats had not eaten for so long, so one expects the topic to remain the same, namely the whole set of cats. (Indeed, most informants said that they accept $b$ only if some additional information about the older cats is given in a subsequent sentence.) Despite its implausibility, the partial interpretation is still the most straightforward interpretation to my informants. Note, further, that the subset interpretation does not seem to be related to any particular intonational configuration of the link. I piccoli is uttered with a normal intonation and still it is interpreted as a subset of cats. Consider now, instead, a similar English example, taken from Hendriks and Dekker (1996).

a. Ten guys were playing basketball in the rain.

b. The fathers were having fun.

Hendriks and Dekker say that if the fathers does not bear a B-accent, the fathers and ten guys have the same referent (the ten guys are the fathers). If the fathers bears a Baccent, on the contrary, the fathers are just a subset of the ten guys, namely, among the ten guys, some are fathers, but others are sons. Thus, it is the presence of the B-accent that triggers a partial interpretation, where the fathers are set against the non-fathers. Unlike what happens in Italian, in English the presence of the accent seems to be crucial to identify the set of alternatives.

A comparison between Italian and French is also useful to understand the Italian data. In the example below from Delais-Roussaire et al. (2002), the right dislocated le dimanche bears a 'C-accent'. Marandin et al. (2002) characterize a C-accent as a sharp rise of the intonational curve, a lengthening of the onset of the accented syllable, and a rise of intensity. While the phonetic characteristics may differ from those of the English B-accent and the German T-accent, the discourse properties seem to be mostly the same (see discussion in Marandin et al., 2002). As Delais-Roussarie et al. explain, with a Caccent, le dimanche gets a contrastive interpretation, namely the sentence implicitly calls for a continuation such as: Il fume la PIPE les autres jours 'As for the other days, he smokes the pipe'.
A: Qu'est-ce qu'il fume?
'What does he smoke?'
B: Il fume les cigarettes, le dimanche.
he smokes the cigarettes the Sunday

compressed pitch accent (cf. e.g. Grice1995, Ladd 1996, D’Imperio 2002, Grice et al. 2005, a.m.o.). Further work on the pragmatics-prosody interface of these constructions would be necessary to test the hypothesis that a pitch accent can also be present on a CLRD under certain pragmatic conditions. See also the observations in the following footnote. 
'On Sunday he smokes cigarettes'

In the corresponding Italian exchange, an answer with the same word order is less acceptable:
A: Che cosa fuma?
'What does s/he smoke?

B1: ?(?) Fuma SIGARETTE, la domenica.

s/he-smokes cigarettes the Sunday

B2: La domenica fuma SIGARETTE.

the Sunday s/he-smokes cigarettes

'On Sunday s/he smokes cigarettes'

A contrastive interpretation of la domenica would be expected in this exchange. In fact, the question is not about what a certain person smokes in a certain day of the week or period of time, but rather what this person smokes in general. Therefore, the specification of la domenica in the answer triggers a contrast between what this person smokes on Sunday and what she smokes on other days. The contrastive interpretation, however, is not available in a right dislocated position, so the answer results inappropriate. Six out of nine informants fully reject the sentence, two find it odd, and one accepts it, but still prefers B2. One of the informants who find B1 odd - a nonlinguist - fully rejects $\mathrm{B} 2$, so he finds $\mathrm{B} 1$ preferable to $\mathrm{B} 2$. As he explained, the reason why he didn't accept B2 is precisely because he found too odd that a person could smoke cigarettes on Sunday and something else the other days. In other words, he got a contrastive reading for B2, but rejected it because it didn't make sense given his world knowledge. So he preferred B1 precisely because such a sentence does not have a contrastive reading: by uttering la domenica the speaker is just providing additional information about when the relevant person smokes. The sentence though is still odd, because la domenica does not have an antecedent in the question, as a tail should have. Note that la domenica in the Italian example, unlike le dimanche in the French one, is (and can only be) de-accented. Thus, while in French, analogously to what happens in English, a particular intonation determines the discourse function of the background expression, in Italian on the contrary, what is crucial is the position the expression occupies in the sentence. ${ }^{25}$

Consider finally the example below, provided to me by an anonymous reviewer. The reviewer says that this example contradicts my claim that in Italian a right dislocated element does not evoke alternatives. La domenica evokes a set of alternatives with respect to weekdays: Gianni is out on Sundays, but possibly in on other days.

$$
\text { A: C'è Gianni? }
$$

\footnotetext{
${ }^{25}$ The reviewer who thinks that two different intonations are available for the CLRD in (32b') also thinks that two different intonations are available for la domenica. It seems to me that if an accent on the temporal adverb (as well as on other right dislocated material) is present, then it must be preceded by a clear pause. I suspect that the pause indicates that the dislocation represents a separate (elliptical) assertion, and that the accent is therefore a focal, not a topical one. In other words, the temporal adverb would not represent the topic (what the answer is about), but rather additional information that the speaker chooses to give, independently from the question he is asked.
} 
'Is John home?' (Asked on a Sunday)

B: No, va allo stadio a vedere la PARTITA, la domenica.

no he goes to-the stadium to see the match the Sunday

'No, he goes to the stadium to see the football match, on Sunday'

As the reviewer (a native speaker of Italian) observes, an exchange like (36) can only be uttered on a Sunday. The reviewer suggests that in that way, the post-focal expression has a referent in the situational context, so it can be interpreted as a tail. While I perfectly agree with this intuition, I also argue that there is no contrastive interpretation involved in such an exchange. The question refers to the present day, and does not say anything about other days. What interests the speaker is whether Gianni is at home at the moment of her call. La domenica is not meant to contrast with other days, but simply to explain that 'Gianni being at the stadium' holds for the present day. ${ }^{26}$

\subsubsection{Summary}

In the first part of this paper I have proposed that a link indicates a topic shift and, as a consequence of this property, that an alternative set can always be evoked by the link. The alternative set can be relevant or not in the context. When the set is relevant, the link gets a contrastive interpretation. A tail, on the other hand, is not a shifting topic, so its referent is not sorted from possible alternatives. From the unavailability of an alternative set, it follows that a tail can never be interpreted contrastively.

The difference between link and tail is indicated by the position of the topic expression in Italian. A first comparison with English and French data seems to show that these languages, on the contrary, make a larger use of intonation to mark such a distinction. Further work is however necessary to better understand the relation between intonation and Information Structure both in these languages and in Italian.

\section{Focus-pre-posing as background post-posing}

In the following sections, we will observe a strong parallelism between CLRD on one hand, and Post-Focal Background in sentences with a left peripheral focus on the other, which I will call PFB. I will conclude that the properties of tails are shared by all material that is post-focal, also by material that is not commonly analyzed as right dislocated. In section 4.3, I will further show that this parallelism is supported by recent syntactic analyses of PFB that treat it precisely as right dislocated material.

\subsection{Post-focal material cannot be contrastive}

So far we have seen that tails are right dislocated expressions and always post-focal, while links are left dislocated expressions and always pre-focal. Rizzi (1997) gives an example where a CLLD occupies a position lower than the left peripheral focus. The example is reported below.

(37) Credo che domani QUESTO a Gianni (gli) dovremmo dire.

\footnotetext{
26 As noted by a reviewer, if the question in (35) is not a generic one, but rather, the speaker is asking about the smoking activity of that moment (e.g., the speaker sees that person smoking but cannot see what she is smoking), the answer in (35B1) too becomes acceptable when uttered on a Sunday.
} 
I-believe that tomorrow this to Gianni to-him ${ }_{\mathrm{cl}}$ we-should say

'I believe that tomorrow we should say THIS to Gianni'

What discourse function does the lower CLLD have? For Rizzi, both the pre-focal expression domani and the post-focal one $a$ Gianni are topics, and they occupy a TopP preceding and a TopP following the focus respectively. Frascarelli and Hinteroelzl (2007) argue that Rizzi's TopPs host two different elements: the pre-focal one hosts a shifting topic, the post-focal one a continuous (or familiar, in their terminology) topic. Similar observations are made by Samek-Lodovici (2006) and Neeleman and van de Koot (2006). Within the present proposal, Frascarelli and Hinterhoelzl's observation means that the post-focal element is a tail. This claim is supported by the fact that the post-focal topic expression cannot be interpreted contrastively (hence, it cannot be a link). The example below shows that.

A: Ai gemelli (gli) ha scritto qualcuno?

'Did anybody write to the twins?

B1: A Ugo TUTTI (gli) hanno scritto.

to Ugo all to-him ${ }_{\mathrm{cl}}$ have written

'As for Ugo, EVERYBODY wrote him'

B2: \# TUTTI, a Ugo (gli) hanno scritto.

all to Ugo to-him ${ }_{\mathrm{cl}}$ have written

Since the question is about the twins, Ugo in the answer is interpreted as a member of the alternative set made of Ugo and his twin-brother. ${ }^{27}$ Such an interpretation cannot arise in B2, because the CLLD occupies a position below the focus. The impossibility for a post-focal element to be contrastive has also been observed in other languages. An example is the German minimal pair provided by Büring (1997:65):

A: Wer hat die älteren Stücke von Brecht gelesen?

'Who read Brecht's earlier plays?'

B1: ?* ICH habe die älteren Stücke von Brecht gelesen.

I have the earlier plays by Brecht read

B2: Die älteren Stücke von Brecht habe ICH gelesen.

the earlier plays by Brecht have I read

'The earlier plays I read'

If the focus is at the beginning of the sentence, as in B1, no contrastive interpretation is possible for the post-focal topic expression. ${ }^{28}$

In the following sections, further evidence will be given that all post-focal material, either occupying a pre-verbal position or not, has tail-like properties in Italian. Before

\footnotetext{
${ }^{27}$ Otherwise, the answer would not be congruent, given that the question is about the twins. If Ugo is one of the twins, the answer is partial but at least not unrelated to the question.

${ }^{28}$ See also the study by Skopeteas and Féry (2006) on pairing answers in German, Georgian, English, and Greek.
} 
doing that, I want to mention the fact that according to some scholars, a post-focal, preverbal topic expression like $a$ Gianni in (37) or a Ugo in (38) is not a CLLD. In particular, as we will see in section 4.3, Samek-Lodovici (2006, forthcoming) treats the post-focal constituent (including the preverbal DP) as right dislocated. Interestingly, his analysis will allow us to maintain a parallelism between a left peripheral syntactic position and a link, and a right dislocated syntactic position and a tail.

\subsection{Post-focal background as tail}

In this section, I will draw a parallelism between CLRD, as in (40), and Post-Focal Background in sentences with a left peripheral focus (PFB), as in (41).

(40) $\mathrm{Li}$ ho prestati ad ANNA, gli appunti. them $\mathrm{cl}_{\mathrm{cl}}$ I-have lent to Anna the notes

'I lent ANNA my notes'

\section{PEB \\ Ad ANNA ho prestato gli appuntí}

to Anna I-have lent the notes

'It's ANNA who I lent my notes to'

We will see that the properties of tails, which we have ascribed so far to right dislocated material, are shared by all material that is post-focal, as the data in the previous section already hinted at.

\subsubsection{Post-focal material requires an antecedent}

We said above that a defining property of a tail is that it is always discourse old, namely it always requires an antecedent in the discourse or at least recoverable from the situational context. In this section, I am going to show that both CLRD and PFB require an antecedent, and that the antecedent can be in the previous sentence, in the previous discourse, or recoverable from the situational context.

The example below (from the LIP corpus) shows a sentence with a CLRD whose antecedent is in the previous sentence. The antecedent is underlined in A.

$$
\begin{aligned}
& \text { A: Io se vuoi ti lascio anche le ricevute. } \\
& \text { I if you-want to-you }{ }_{\mathrm{cl}} \text { leave also the receipts } \\
& \text { 'If you want, I can also leave you the receipts' } \\
& \text { B: No, ora non me le LASCI, le ricevute. } \\
& \text { no now not to-me them }{ }_{\mathrm{cl}} \text { you-leave the receipts } \\
& \text { 'No, for now you won't LEAVE me the receipts' }
\end{aligned}
$$

The following contrasting pair from the C-Oral Rom corpus (Cresti and Moneglia, 2005 ) illustrates a case where the second sentence contains a PFB. ${ }^{29}$

\footnotetext{
${ }^{29}$ The C-Oral Rom consists of a collection of monologues, dialogues, and conversations with various degrees of spontaneity in different Romance languages.
} 
MIC: È chiaro, perché io devo imporre le mie idee [...] se credo nelle mie idee 'Of course, as I have to impose my ideas [...] if I believe in my ideas'

\section{MAR: OGNUNO vuole imporre le sue idee, però...}

each-one wants to-impose the his ideas but

'EVERYONE wants to impose their own ideas, but...'

The underlined part in A constitutes the antecedent for the PFB vuole imporre le sue idee ' $\mathrm{s} / \mathrm{he}$ wants to impose his/her own ideas' in B.

Another context, in which the antecedent is in the previous sentence, is a questionanswer pair. Consider the constructed examples below:

\section{A: Chi ha comprato il giornale? \\ 'Who bought the newspaper?'}

\section{B1: ?? ANNA ha comprato il giornale.}

Anna has bought the newspaper

B2: ? L'ha comprato ANNA, il giornale.

$\mathrm{it}_{\mathrm{cl}}$ has bought Anna the newspaper

\section{B3: ? ANNA, l'ha comprato.}

Anna $\mathrm{it}_{\mathrm{cl}}$ has bought

B4: L'ha comprato ANNA.

$\mathrm{it}_{\mathrm{cl}}$ has bought Anna

B5: Anna.

In this context, post-focal material causes a redundancy effect, which is stronger when the post-focal part is the entire sentence, as B1 illustrates. ${ }^{30}$ I argue that the reason for redundancy has to do with the predictability of an answer given its question. An answer must be congruent to its question, so it is perfectly derivable from it: the focus corresponds to the wh-phrase, and the background is the same as the remaining part of the question (cf. Tancredi, 1992, Büring, 2007, a.o.). Therefore, the post-focal background in an answer has an antecedent that is readily recoverable from its question.

The PFB can occur in a contrastive context, as we have seen in (43), or in the following example:

ANNA ha comprato il giornale, non Marco.

\footnotetext{
${ }^{30}$ The question mark in B2 and B3 does not mean that these answers are unacceptable, but simply indicates the slight redundancy feeling that the presence of post-focal material triggers. See also discussion about (25B1). As for B4, the reason for its full acceptability could be related to the fact that there is a tendency for the verb to be part of the focus. Such a tendency presumably indicates that speakers prefer to make predication and new information coincide (cf. the discussion on pre-posed focus in Vallduví 1992:119-120). It could then be the case that the verb in B4, although given in the question, is accepted because the focus has a predicative part. If the verb follows the direct object, it cannot be interpreted as focused, but if it precedes the object, it can be interpreted as part of the focus for the way focus projection applies (cf. Cinque 1993).
} 
'ANNA bought the newspaper, not Marco'

Why no redundancy effect occurs here? Given that the speaker explicitly contrasts Anna with Marco, (45) does not need to be immediately preceded by the contrasted proposition ('Marco bought the newspaper'), but the proposition can be inferred implicitly from the context. Alternatively, the proposition can be present, but not be salient anymore in the discourse. In both cases, the PFB is not felt as redundant. But even when the antecedent is given in the immediately preceding sentence, as in (43), a contrasting pair is different form a question-answer pair. The person who utters the first sentence does not expect a contrasting statement from his/her interlocutor. There is no congruence requirement for a contrasting pair, as there is for a question-answer pair. So it is harder for the hearer to reconstruct the sentence from a fragment. ${ }^{31}$

Note that the redundancy problem does not occur with pre-focal background in answer like B6:

(44) A: Chi ha comprato il giornale?

'Who bought the newspaper?'

B6: Il giornale, l'ha comprato ANNA.

the newspaper $i_{\mathrm{cl}}$ has bought Anna

'As for the newspaper, ANNA bought it'

In Brunetti (2004), the acceptability of B6 is ascribed to the fact that ellipsis can occur when the focus has moved to the left periphery, but not when the focus is in situ, as ellipsis cannot apply to a non-constituent (il giornale, l'ha comprato). Although I believe in the constituency constraint for ellipsis, I do not think it is relevant to explain the acceptability of B6. If the acceptability were due to the impossibility of doing ellipsis, the sentence would rather sound ungrammatical. A different explanation is available if we take into account what I have proposed in this paper (cf. also Brunetti, in press). The answer in B6 can be analyzed as (25B2). The CLLD is a link so its presence is legitimated by the fact that the speaker intends to contrast the newspaper with other things. In fact, we easily interpret B6 as if the speaker had in mind that other things other than the newspaper may or should have been bought. ${ }^{32}$

\footnotetext{
${ }^{31} \mathrm{Cf}$. Brunetti (forthcoming). See also Brunetti (2004) for a (partly) different treatment of the difference between question-answer pairs and contrasting pairs.

${ }^{32}$ Consider also the example below, where the verb is elided. When the order of the remaining arguments is background-focus, ellipsis of the verb does not affect the acceptability of the answer, while when the order is focus-background, it does.

(i) A: Ad Anna, che cosa regalerai?

'As for Anna, what will you give her (as a present)?'

B1: Ad Anna, Un LIBRo. to Anna a book

B2: ?? UN LIBRO, ad Anna. a book to Anna

I have tested the acceptability of these answers on 8 speakers: none of them found the answer in B2 acceptable. In B1, ad Anna is a link, licensed by the necessity to evoke a contrast between Anna and other relevant individuals. Since the verb does not get a contrastive interpretation, it can be omitted. In B2, on the contrary, ad Anna is a tail, so there should be no difference between the object and the verb, namely there should be no reason for the omission of the verb but not of the object. This produces the awkwardness of this construction.
} 
Note finally that the answer would not be very good if the pre-verbal background did not contain a CLLD, as in the example below:

(44) A: Chi ha comprato il giornale?

'Who bought the newspaper?'

B7: ?? Ha comprato il giornale ANNA.

has bought the newspaper Anna

It seems to me that the level of acceptability of this answer is the same as that of B1. In other words, the non-dislocated material preceding the focus cannot be considered as a link. This is the only case in which pre-focal material behaves like a tail. It follows that left-dislocation of the object is crucial in order to have a tail interpretation.

Going back to the parallelism between CLRD and PFB, both elements can also have an antecedent that is recoverable in a not recent discourse context (it is not salient anymore). The presence of the CLRD or of the PFB is actually a way to 'update' the saliency of that antecedent. The example below from the LIP corpus illustrates the case of CLRD. Six exchanges earlier, the speaker's mother was complaining about the speaker touching food without washing his hands. Then the conversation changes, until the speaker utters (46).

(46) Mamma, quand'ero piccino come me le LAVAVO le mani?

mum when I-was little how REFL $L_{\mathrm{cl}}$ them $\mathrm{cl}_{\mathrm{I}} \mathrm{I}$-washed the hands

'Mum, when I was little, how did I wash my hands?'

Le mani 'the hands' is introduced as a CLRD, therefore as a tail. In fact, its antecedent can be recovered in that previous conversation between the speaker and his mother. A similar example with PFB can be constructed. The antecedent for the PFB has to be recoverable in a previous chunk of discourse, although not a recent one. Consider the following scenario. Anna and Leo are talking about a competition. Leo wonders who won it and Anna tells him who did, but Leo does not recall who that person is. In a later conversation, Anna utters (47), recalling that previous discourse event.

Ecco, vedi quella ragazza laggiù? A LEI hanno dato il premio.

to her they-have given the prize

'See that woman over there? It's HER they give the prize to'

The presence of the PFB implies that there is an antecedent for it in the discourse. Thus, that someone received a prize must have been uttered in prior discourse, and this makes Leo assume that Anna is referring to that previous conversation in which they where talking about who got the prize. It is important to note that the presence of the antecedent in a previous discourse is crucial for the sentence to be acceptable. The sentence could not be felicitously uttered if no previous conversation was made where that someone got a prize was under discussion. This clearly shows that the requirement of an antecedent is a property of PFB as much as it is for a CLRD. An example of the same type taken from the C-Oral Rom corpus is given below:

TAM: ma perché 'un fate, oltre alla torta base del compleanno, tanti biscottini? 
'Why don't you also make lots of cookies, other than the birthday cake?

VER: io volevo fare ... [...] la Barbara voleva fare quelli con il cocco, però I wanted to-do the Barbara wanted to-do those with the coco-nut but non c'ha la ricetta [...] forse la MADDALENA fa dei biscotti $[. .$. not has the recipie perhpas the Maddalena makes some cookies 'I wanted to make... [...] Barbara wanted to make those with coco-nut, but she does not have the recipie [...] and then Barbara will make a cake [...] perhaps MaDDALENA will make some cookies [...]'

The antecedent for the PFB ('make cookies') is mentioned in TAM's utterance, and then VER refers to it with a PFB at the end of her long speech (which I have shortened, as dots within square brackets indicate).

Finally, both the CLRD and the PFB can have an antecedent in the situational context. The example below from the LIP corpus illustrates a case with a CLRD. The sentence opens a dialogue between the speaker, who is a customer, and a post office clerk.

Buongiorno signora, glie lo do a LEI, il biglietto?

good morning madam to-you $\mathrm{cl}_{\mathrm{cl}} \mathrm{it}_{\mathrm{cl}} \mathrm{I}$-give to you the ticket

'Good morning, madam, do I have to give YOU the ticket?'

The sentence is uttered in a situation in which the speaker is presumably holding a ticket and is showing it to the clerk. The CLRD refers to the ticket that is present in the extralinguistic context. This sentence could also have been uttered with il biglietto in a prefocal position, as shown below:

(49)' Buongiorno signora, il biglietto glielo do a LEI?

good morning madam the ticket to-you $\mathrm{cl}_{\mathrm{cl}}-\mathrm{it}_{\mathrm{cl}} \mathrm{I}$-give to you

'Good morning, madam, as for the ticket, do I have to give it to YOU?'

However, the most natural interpretation of this sentence is one where papers or documents other than the ticket are under discussion. The speaker is asking about the ticket in contrast with such documents. This contrastive effect is given, once again, by the fact that the link evokes alternatives. The definite article of il biglietto signals that the ticket was already under discussion in a previous conversation. Therefore, the fact that il biglietto is introduced as a link favors an interpretation where the ticket is sorted among other possible documents that were under discussion as well.

A perfectly parallel example with a sentence containing a PFB, still from the LIP corpus, is given below. Speaker B is a front-office clerk, and speaker A is a customer who has given her the wrong document.

A: Questo è il ticket.

'Here is the receipt' 
B: No, questo non mi interessa; un DOCUMENTO mi deve dare, signora. no this not to-me $\mathrm{cl}_{\mathrm{cl}}$ interests an I.D. to-me $\mathrm{cl}_{\mathrm{cl}}$ you-must give madam 'No, I don't need this; it's your I.D. you have to give me, madam'

Speaker A presumably hands the receipt to the clerk while she says 'Here's the ticket'. Therefore, the action of 'giving something to the clerk' is 'present' in the situational context. This gives the PFB the antecedent it requires. Even in this case, the recoverability of the antecedent makes the PFB acceptable. The sentence would not be felicitous if it was not implicitly assumed from the situation that speaker A has to give something to the clerk. So the presence of an antecedent is an indispensable property of PFB. A corresponding sentence with pre-focal background is also possible:

(50)' B: No, questo non mi interessa; mi deve dare un DOCUMENTO, signora. no this not to-me $\mathrm{cl}_{\mathrm{cl}}$ interests to-me $\mathrm{cl}_{\mathrm{cl}}$ you-must give an I.D. madam 'No, I don't need this; you have to give me your I.D., madam'

In this case, the sentence mi deve dare un documento is presumably interpreted as all focused (given that focus can project from the accented word documento).

\subsubsection{Further similarity between CLRD and PFB: contrastive focus}

Among the examples seen in the previous section with a CLRD (42B, 44B2, 46 and 49), two of them (42B and 49) have a focus with a contrastive/corrective interpretation. In (42B), the polarity of the sentence is contrasted. In (49), the speaker is wondering if the person who has to receive the ticket is the clerk or somebody else. Among the sentences with PFB (43, 45, 47, 48, 50B), the focus is contrastive in (43), (45), and (50B). In (43), the speaker is contrasted with everybody, in (45), Anna is contrasted with Marco, and in (50B), the I.D. is contrasted with the receipt. As a matter of fact, in sentences containing post-focal background, the occurrence of a contrastive focus, although not obligatory (46), (47), (48) do not have $\mathrm{it}^{33}$ - is rather frequent. This fact has led some authors (see e.g. Rizzi, 1997, É. Kiss, 1998, Zubizarreta, 1998, a.o.) to propose that a left peripheral focus is inherently contrastive and that the focused element carries a contrastive focus feature that has to be checked (in the sense of Chomsky, 1995) in a specific position in the $\mathrm{CP}$ area. Focus has to move to that position as a consequence of its contrastive interpretation, and this explains the relation between left peripheral position and contrast. Belletti $(2001,2004)$ extends this analysis to a contrastive focus in a middle position: she proposes a derivation where the focus ends up occupying the same left peripheral position, where it checks its contrastive focus feature.

Following various scholars who worked from different perspectives and on different languages, I assume instead that the contrastive interpretation of focus is a discoursedependent phenomenon, and that contrast is not a category of grammar (see e.g. Bolinger, 1965, Vallduví, 1992, Geluykens, 1992, Rooth, 1992, Lambrecht, 1994, among many others; see also Brunetti, 2004 for various pieces of evidence against a grammatical encoding of contrastive focus) ${ }^{34}$. Given this assumption, a focused element

\footnotetext{
${ }^{33}$ See Brunetti (2004) for further examples of sentences with left peripheral or middle focus that do not have a contrastive interpretation.

${ }^{34}$ This assumption is compatible with what I say above about contrast in links. In that case too, contrast comes out as a consequence of the discourse context, and is not an inherent property of links.
} 
can be contrastive or not depending on the context. But why should a focus in a sentence with post-focal material be frequently contrastive? The explanation I give is that a sentence with post-focal material is perfectly compatible with a contrastive interpretation, because post-focal material is always discourse old, and contrast requires the existence of an explicit or implicit proposition in the discourse to contrast with. If a sentence contrasts or corrects a certain statement, clearly it implies that that statement was believed to be true by some participant in the conversation and therefore explicitly or implicitly present in the common ground. For instance, if someone says (41) (repeated below) in order to correct the identity of the person who borrowed the notes, it is obvious that, before in the discourse, it was implicitly or explicitly assumed by the interlocutor that someone other than Anna had borrowed the notes.

\section{(41) Ad ANNA ho prestato gli appunti.}

to Anna I-have lent the notes

'It's ANNA who I lent my notes to'

If we assume that the PFB in (41) has tail-like properties, its presence with a contrastive focus is perfectly explained, because a tail has always an antecedent in the discourse or in the situational context. ${ }^{35}$ Along the same reasoning, the attribution of tail-like properties to PFB allows us to explain why a sentence like (41), when uttered or quoted in isolation, is usually interpreted as contrastive. If a sentence has PFB, the

hearer/reader will know that such a background must have been mentioned in previous discourse or at least must be recoverable in the situational context. Thus, if no context is explicitly provided, the hearer/reader will create an appropriate context where an antecedent for the PFB can be recovered. Crucially, the existence of an antecedent can be readily accommodated if contrast is imagined between two foci, as explained above. $^{36}$

\subsection{PFB and right dislocation}

The data and discussion in parr. 4.2.1 and 4.2.2 lead us to conclude that, from the point of view of Information Structure, PFB has tail-like properties. Nevertheless, this conclusion appears to be questioned by the syntax of such a construction. According to

\footnotetext{
${ }^{35}$ For a more detailed analysis and a richer set of data on this topic, see Brunetti (in press), and for a partly different account, see Brunetti (forthcoming).

${ }^{36}$ Similar observations are also made by Wedgwood (2007) for Hungarian sentences with focus preposing, like the following:

(i) JÁNOST hívták meg.

Jánost $_{\text {acc }}$ they-invited VM

'They invited JÁNOST'

Wedgwood claims that a sentence like (i) (where 'VM' indicates the verbal modifier) is not usually found in answers to questions, because the fragment answer would be a better option (cf. my discussion about 44B1). Consequently, a full sentence like (i) in isolation "tends to be associated with contexts in which the IS of the sentence is not predetermined by a context-question" (Wedgwood, 2007:6-7). Such contexts would be those where the focus gets a particular interpretation (exhaustive, in Hungarian).
} 
most studies, a CLRD occupies a position outside the clause, as illustrated in the representation of (40) given below: ${ }^{37}$

(40)' [IP Li ho prestati ad ANNA $\left.\mathrm{t}_{\mathrm{j}}\right]$ [DP gli appunti $]_{\mathrm{j}}$. them $_{\mathrm{cl}}$ I-have lent to Anna the notes

Depending on the analysis, the CLRD is either adjoined to the verb by rightward movement (e.g. Vallduví, 1992), or it is moved to a position in the left periphery, and then followed by movement of remnant material to an even higher position (see e.g. Villalba, 1998, Cardinaletti, 2002, Belletti, 2004, Frascarelli, 2004). As I have mentioned in the previous section, most syntactic accounts of a sentence like (41), on the contrary, argue that that construction results from movement of the focused element to a left peripheral, dedicated syntactic position in the $\mathrm{CP}$ area, right above the IP (FocP, if we follow Rizzi, 1997), leaving a trace inside the clause (see Brody, 1990, Rizzi, 1997, É. Kiss, 1998, Zubizarreta, 1998, among others). The focus moves to that position in order to check a formal feature in the sense of Chomsky (1995). A simplified representation of this kind of analyses is given below:

$$
\left[\text { FocP }[\mathrm{PP} \text { Ad ANNA }]_{j} \ldots \text {... [IP ho prestato gli appunti } t_{j}\right] \text {. }
$$

to Anna I-have lent the notes

With an analysis of left peripheral focus like (41)', PFB and CLRD are two completely different syntactic objects: PFB is the remnant IP after focus movement, while CLRD is an element that has moved out of the clause.

Note that a complete matching between syntax and IS is not in principle necessary. Following Vallduví (1992), I assume that syntax and IS are independent levels of the grammar. Thus, it is in principle possible that the uniform pragmatic properties of PFB and CLRD do not correspond to uniform syntactic representations. Nevertheless, we have seen above that Italian (like Catalan, as Vallduví illustrates) is a language where a correspondence normally occurs between the IS representation and the syntactic representation. Therefore, if my conclusion about the pragmatic uniformity of PFB and CLRD is correct, a syntactic uniformity of PFB and CLRD is also plausibly expected.

Furthermore, a syntactic analysis where the contrastive focus occupies a dedicated position in the left periphery contradicts what I have said in section 4.2.2, namely that a contrastive interpretation of focus is just an effect of the discourse context (so it is not tied to a particular syntactic structure). But more importantly, it contradicts what I have shown all throughout this paper, namely that word order does not say anything about focus, but rather about the link or tail status of the background.

Interestingly, in a recent work, Vieri Samek-Lodovici (Samek-Lodovici, 2006) proposes on completely independent grounds the syntactic similarity that is expected between the two constructions from my pragmatic conclusions. Instead of deriving left peripheral focus from movement, Samek-Lodovici proposes that the PFB occupies a right dislocated position, outside the IP. The idea that PFB is a right dislocation had already been suggested in previous literature (see references quoted in his work), but he provides a much more solid bulk of evidence. In particular, he updates and develops the

\footnotetext{
${ }^{37}$ Two exceptions are Kayne (1994), who proposes an in situ account for CLRD, and Cecchetto (1999), who proposes that the CLRD is generated in argument position and moves to a syntactic position within the clause.
} 
proposal made by Vallduví (1992) for Catalan. Vallduví observes that a CLRD never provides a right detached, non-focused verb, while focus pre-posing precisely gives rise to a construction where the verb is non-focused. Therefore, the two constructions turn out to be complementary, and to realize together all the possible sentences containing a focus-background sequence. Starting from this observation, Vallduví pursues the idea of a uniform syntactic account of the two constructions: he proposes that for both CLRD and PFB, what we are dealing with is right detachment outside the clause by rightward movement. For PFB, assuming that the verb too is detachable, he suggests that the arguments and the verb move independently to the right. Samek-Lodovici retains Vallduví's original idea and applies it to Italian, but revises the analysis by taking into account Kayne's (1994) ban on rightward movement. He basically extends to PFB the double-movement account proposed by some scholars for right dislocation. In the case of a sentence with an initial focus, the derivation has in fact three steps: first, the focused element is removed out of the IP, to an adjoined position; second, the remnant IP is dislocated to a TopP position; third, the remnant IP (made of the sole focus) is further moved to a higher projection, above the TopP. His representations of both a CLRD and a PFB are given in (51b) and (52b) respectively. Al vincitore 'the winner' and abbiamo dato al vincitore 'we have given to the winner' are both 'extracted' out of the IP; precisely, they are both right detached.

a. Gli abbiamo dato una MEDAGLIA al vincitore. to-him $\mathrm{cl}_{\mathrm{l}}$ we-have given a medal to-the winner

b. [XP [IP pro gli abbiamo dato una MEDAGLIA $\left.\left.\left.\mathrm{t}_{\mathrm{i}}\right]_{\mathrm{k}} \varnothing_{\mathrm{x}}\left[\text { TopP }_{\text {TPP }} \text { al vincitore }\right]_{\mathrm{i}} \varnothing_{\mathrm{Top}} \mathrm{t}_{\mathrm{k}}\right]\right]$

a. Una MEDAGLIA abbiamo dato al vincitore.

a medal we-have given to-the winner

b. [XP [DP una MEDAGLIA $\left.\left.]_{\mathrm{n}} \mathrm{t}_{\mathrm{i}}\right]_{\mathrm{k}} \varnothing_{\mathrm{x}} \quad\left[\mathrm{TopP}\left[\text { pro abbiamo dato } \mathrm{t}_{\mathrm{n}} \text { al vincitore }\right]_{\mathrm{i}} \varnothing_{\mathrm{Top}} \mathrm{t}_{\mathrm{k}}\right]\right]$

Within this account, even a post-focal pre-verbal object such as a Gianni in (37) can be analyzed as right dislocated. While a pre-focal DP is a real case of left-dislocation to a position in the C area, as in Rizzi's (1997) account, the post-focal DP position is the result of the following operations: fronting of the DP before dislocation of the IP, followed by further dislocation of the DP to a higher position, and eventually movement of the remnant IP. Simplifying, the object and the rest of the sentence move independently to end up in a post-focal position. I refer to Samek-Lodovici (forthcoming) for further syntactic details. ${ }^{38}$

38 One of Samek-Lodovici's arguments in favor of this analysis is the difference in clitic resumption: obligatory with a pre-focal direct object (ia), and obligatory absent with a post-focal one (ib):

(i) a. I fiori, a MARIA, li abbiamo dati.

the flowers to Maria them $\mathrm{cl}_{\mathrm{cl}}$ we-have given

'The flowers, we gave them to MARIA'

b. A MARIA, i fiori, abbiamo dato.

to Maria the flowers we-have given

'We gave the flowers to MARIA'

The difference is less clear with an indirect object such as a Gianni in (37), because the clitic is not obligatory absent but optional (see iib). Note, however, that the clitic is not obligatory, but again optional also with a pre-focal indirect object (iia). Therefore, the presence of the clitic neither is evidence in favor nor against the left-dislocated status of the object.

(ii) a. A Mario, dei FIORI (gli) ho portato. 
It is important to emphasize that Samek-Lodovici's proposal is made independently from the pragmatic characteristics of the PFB. The main pieces of evidence he provides for the external position of post-focal material are syntactic. By studying $\mathrm{N}$-word and NPI licensing, for instance, he shows that material after the focus lies outside the ccommanding domain of material within the focus, which proves the clause external status of post-focal material. He also shows that wh-interrogatives can be dislocated to the right of a sentence initial focus if they are discourse old, and therefore, that there is no incompatibility between a sentence initial focus and a wh-phrase (so against Rizzi, 1997, there is no evidence that they occupy the same left peripheral position in the CP field).

Samek-Lodovici concludes his analysis with the following words: "We have to abandon the idea of a fixed focus projection and accept that the position of focus is dynamically determined by the concomitant action of two factors. On factor is RD [right dislocation, LB], which determines how far focus occurs form the right edge of the clause (and, symmetrically, how close to its left edge). The other is rightmost stress assignment [...]" (Samek-Lodovici, 2006:34). The former of these two factors is precisely what I have been claiming in this paper on the basis of completely different evidence: the position of focus does not depend on the characteristics of the focus itself, but rather on those of the background, which can in part or entirely be a tail. Put it differently, the position of the focus is a consequence of the necessity, given the speaker's informative goals, that some or the entire part of the background be understood as a tail.

\section{Conclusions}

In this paper I have described the properties of links and tails in Italian. I have argued that links are sentence initial, pre-focal expressions, and tails are post-focal, right dislocated expressions. I have proposed, following Vallduví (1992), that links are shifting topics. I have in fact shown that after a topic is introduced in the discourse in a link-position, it is not realized in that position in subsequent sentences as far as the topic remains the same. I have further shown that the function of a link remains that of a topic shift even when the link appears to refer to the current topic of the discourse. When this happens, the shifting function can still be seen in the interpretive effect that it yields. In particular, in an answer to a wh-question like (25B2), the shifting function of the link explains the contrastive interpretation that is naturally given to such an answer. The presence of a link in (25B2) is not expected, because the topic of an answer should be the same as that of its question. The unexpectedness of the link makes the listener infer that the speaker wants to sort again the same topic in order to highlight the contrast between that topic and its contextual alternatives. If the characteristics of the context do not admit alternatives to the referent of the link, then the link results unacceptable, as

to Mario some flowers to-him ${ }_{\mathrm{cl}}$ I-have brought

'To Mario, it's some flowers that I brought'

b. Dei FIORI a Mario, (gli) ho portato.

some flowers to Mario to-him ${ }_{\mathrm{cl}}$ I-have brought

'It's some flowers that I brought to Mario'

Given further, that an indirect object clitic can resume a focused item (see Benincà 1988[2001]:151-152),

I suggest that its presence cannot be taken as a consequence of a left-dislocated position of the object. I

leave a development of this idea to future research.

I thank Vieri Samek-Lodovici for his comments on this point. 
shown in (30). As for a tail, since it is not a shifting topic, its referent is not sorted from possible alternatives. From the unavailability of alternatives, it follows that a tail can never be interpreted contrastively. This explains why a contrastive interpretation does not arise in an answer like (25B1). I have eventually observed that a difference seems to exist between Italian and other languages in the linguistic marking of links: unlike in English or French, in Italian the link is not signaled by a particular intonation. Further work however is needed to confirm this observation.

In the last part of the paper, I have shown that all post-focal material has tail-like properties. I have shown that a contrastive interpretation (which is a property of links) is only possible for background material that precedes the focus, and I have observed strong similarities between the pragmatic properties of CLRD and those of PFB. I have eventually shown how Samek-Lodovici's (2006) syntactic account of Italian left peripheral focus, where the PFB is analyzed as right dislocated material, provides independent syntactic support to these findings.

\section{Acknowledgments}

I thank the three anonymous reviewers for very useful comments, suggestions, and criticisms. I thank Enric Vallduví, Louise McNally, Stefan Bott, Maribel Romero, Alex Alsina, and Laia Mayol for their helpful discussions and comments on this work at earlier stages of its preparation. For native-speaker judgments, I thank Laura Bafile, Valentina Bianchi, Giuliano Bocci, Caterina Briguglia, Cosimo Brunetti, Berta Calvani, Carlo Cecchetto, Gloria Cocchi, Francesco Costantini, Elisabetta D'Agata, Elisa Di Domenico, Laura Fambrini, Stefania Fei, Eva Fuochi, Alessandra Giorgi, Silvia Givone, Giuseppe Longobardi, Maurizio Manetti, Benedetta Melozzi, Edoardo Pasca, Tommaso Roscilde, and Silvia Sottini. All remaining errors are my own responsibility. This work is supported by the Spanish Ministry of Education through the 'Juan de la Cierva' postdoctoral fellowship.

\section{References}

Alexiadou, A., Anagnostopoulou, E., 1998. Parametrizing AGR: word order, Vmovementand EPP-checking. Natural Language \& Linguistics Theory 16, pp. 491-539.

Arregi, K., 2003. Clitic left dislocation is Contrastive Topicalization. In: Proceedings of the $26^{\text {th }}$ Annual Penn Linguistic Colloquium, UPenn Working Papers in Linguistics 9, 1, Penn Linguistics Club, pp. 31-44.

Barbosa, P., 1997. Subject Positions in the Null Subject Languages. In: Seminarios de Linguistica 1, Universidade do Algarve, UCEH, Faro, pp. 39-63.

Belletti, A., 2001. Inversion as focalization. In: Hulk, A., Pollock, J.-Y. (Eds.), Oxford Studies in Comparative Syntax: Subject Inversion in Romance and the Theory of Universal Grammar. Oxford University Press, Oxford, pp. 60-90.

Belletti, A., 2004. Aspects of the low IP area. In: Rizzi, L. (Ed.), The Cartography of Syntactic Structures, vol. 2: The Structure of IP and CP. Oxford University Press, Oxford, pp. 16-51. 
Benincà, P. 1988 [2001]. L'ordine delle parole e le costruzioni marcate. In Renzi, L., Salvi, G., Cardinaletti, A. (Eds.), vol. 1: Grande grammatica italiana di consultazione. Il Mulino, Bologna, pp.129-239.

Benincà, P., 2001. The position of Topic and Focus in the left periphery. In: Cinque, G., Salvi, G. (Eds.), Current studies in Italian syntax, North-Holland, Amsterdam, pp. 38-64.

Berman, R. A., Slobin, D. I. (Eds.), 1994. Relating events in narrative: A crosslinguistic developmental study. Lawrence Erlbaum Associates.

Bolinger, D.L., 1965. Forms of English. Hokuon, Tokyo.

Brody, M., 1990. Some remarks on the focus field in Hungarian. In: UCL Working Papers in Linguistics, 2, pp. 201-225.

Brunetti, L., 2004. A Unification of Focus. Unipress, Padova.

Brunetti, L., 2006. Italian background: links, tails, and contrast effects. In: Gyuris, B., Kálmán, L., Piñon, C., Varasdi, K. (Eds.), Proceedings of the Ninth Symposium on Logic and Language, Research Institute for Linguistics, Hungarian Academy of Sciences, Eötvös Loránd University, Budapest, pp. 45-52.

Brunetti, L., 2007. Left Dislocation in Romance and contrast effects. Talk presented at the Workshop on Contrast, Zentrum für Allgemeine Sprachwissenschaft, Berlin (May 3-4, 2007).

Brunetti, L. in press. On the pragmatics of post-focal material in Italian (left peripheral focus looked at from the other side). In Actes du Colloque International 'Les linguistiques du détachement'. Peter Lang.

Brunetti, L., submitted. On the semantic and contextual factors that determine topic selection in Romance. Special issue of The Linguistic Review, selected papers from the Workshop 'What's the topic?' Radboud Universiteit Nijmegen (Jan. 23-23, 2007).

Brunetti, L. forthcoming. Discourse Functions of Fronted Foci in Italian and Spanish. In: Drufter, A., Jacob, D. (Eds.) Focus and Background in Romance Languages, Studies in Language Companion Series, John Benjamins, Amsterdam.

Büring, D., 1997. The Meaning of Topic and Focus - The 59th Street Bridge Accent. Routledge, London.

Büring, D. 2003. On D-Trees, Beans, and B-Accents. Linguistics \& Philosophy 26, 5, pp. 511-545.

Büring, D., 2007. Intonation, Semantics, and Information Structure. In: Ramchand, G., Reiss, C. (Eds.), The Oxford Handbook of Linguistic Interfaces, Oxford University Press, Oxford.

Butt, M., King, T.H., 1997. Null Elements in Discourse Structure. In: Subbarao, K.V. (Ed.), Papers from the NULLS Serminar, Moti Lal Banarsi Das.

Cardinaletti, A., 1997. Subjects and clause structure. In: Haegemann, L. (Ed.), The New Comparative Syntax. Longman, London, pp. 33-63.

Cardinaletti, A., 2002. Against optional and null clitics. Right dislocation vs. marginalization. Studia Linguistica 56, 1, pp. 29-58.

Chafe, W. L., 1976. Givenness, contrastiveness, definiteness , subjects and topics and point of view. In: Charles N. Li (Ed.), Subject and topic, Academic Press, New York, pp. 27-55.

Cecchetto, C., 1999. A comparative analysis of Left and Right Dislocation in Romance. Studia Linguistica, 53, 1, pp. 40-67.

Chomsky, N., 1995. The minimalist program, MIT Press, Cambridge, MA. 
Cinque, G. 1993. A null theory of phrase and compound stress, Linguistic Inquiry, 24, pp. 239-267.

Cresti, E., Moneglia, M. 2005. C-Oral-Rom. Integrated Reference Corpora of Spoken Romance Languages. John Benjamins, Amsterdam.

De Mauro, T., Mancini, F., Vedovelli, M., Voghera, M., 1993. Lessico di frequenza dell'italiano parlato. Etas, Milano.

Delais-Roussarie, E., Rialland, A., Doetjes J., Marandin, J.-M., 2002. The Prosody of post-focus sequences in French. In: Speech Prosody, Proceedings of the First International Conference on Prosody, pp. 239-242.

Di Eugenio, B., 1990. Centering theory and the Italian pronominal system. In: Proceedings of the $13^{\text {th }}$ International Conference on Computational Linguistics (COLING 90), Helsinki, 270-5.

Di Eugenio, B., 1998. Centering in Italian. In: Walker, M., Joshi, A. K., Prince, E. (Eds.) Centering Theory in Discourse, Oxford University Press, Oxford, pp. 114-137.

D'Imperio, M. 2002. Italian intonation: An overview and some questions. Probus, 14,1, pp. 37-69.

D'Imperio, M., Cangemi, F., Brunetti, L., 2008. The phonetics and phonology of contrastive topic constructions in Italian. Poster presented at the Third Conference on Tone and Intonation (TIE3), University of Lisbon, Lisbon (September15-17, 2008).

É. Kiss, K., 1998. Identificational focus versus information focus. Language 74, 2, pp. 45-273.

Endriss, C., 2006. Quantificational topics. A scopal treatment of exceptional scope phenomena. PhD dissertation, Universität Potsdam.

Frascarelli, M., 2000. The Syntax-Phonology Interface in Focus and Topic Constructions in Italian. Kluwer, Dordrecht.

Frascarelli, M., 2004. Dislocation, Clitic Resumption and Minimality: A comparative analysis of left and right Topic constructions in Italian. In: Bok-Bennema, R., Hollebrandse, B., Kampers-Manhe, B., Sleeman, P. (Eds.), Romance Languages and Linguistic Theory 2002, John Benjamins, Amsterdam/Philadelphia, pp. 99-118.

Frascarelli, M., Hinterhölzl, R., 2007. Types of topics in German and Italian. In: Winkler, S., Schwabe, K. (Eds.), On Information Structure, Meaning and Form, John Benjamins, Amsterdam/Philadelphia, pp. 87-116.

Geluykens, R., 1992. From discourse process to grammatical construction: On leftdislocation in English. John Benjamins, Amsterdam/Philadelphia.

Ginzburg, J., forthcoming. A Semantics for Interaction in Dialogue. CSLI Publications and University of Chicago Press, Chicago.

Grice, M. 1995. The intonation of interrogation in Palermo Italian, Tubingen, Niemeyer.

Grice, M., D'Imperio, M., Savino, M., and Avesani, C., 2005. A strategy for intonation labelling varieties of Italian. In: Jun, S., (Ed.), Prosodic Typology: The Phonology of Intonation and Phrasing. Oxford University Press, Oxford, pp. 362-389.

Grosz, B.J., Joshi, A., Weinstein, S., 1995. Centering: A Framework for Modelling the Local Coherence of Discourse. Computational Linguistics, 21/2, pp. 203-225.

Heim, I., 1983. File change semantics and the familiarity theory of definiteness. In Bäuerle, R., Schwarze, C., von Stechow, A. (Eds.). Meaning, use, and interpretation of language. de Gruyter, Berlin/New York, pp. 164-189. 
Hendriks, H., Dekker, P., 1996. Links without locations. In: Dekker, P., Stokhof, M.(Eds.), Proceedings of the Tenth Amsterdam Colloquium, University of Amsterdam, pp. 339-358.

Jackendoff, R., 1972. Semantic interpretation in generative grammar. MIT Press, Cambrige, MA.

Kayne, R. S., 1994. The Antisymmetry of Syntax. MIT Press, Cambridge, MA

Ladd, D.R. 1996. Intonation Phonology. Cambridge University Press, Cambridge.

Lambrecht, K., 1994. Information structure and sentence form. Topic focus, and the mental representations of discourse referents. Cambridge University Press, New York.

Lambrecht, K, Michaelis, L.A., 1998. Silence accent in information questions: default and projection. Linguistics and Philosophy, 21, pp. 477-544.

Lee, C. 1999. Contrastive Topic: A Locus of the Interface - Evidence from Korean and English. In Turner, K. (Ed.), The Semantics/Pragmatics Interface from Different Points of View (CRiSPI 1), Elsevier Science.

Manzini, M.R., Savoia, L.M., 2002. Parameters of Subject Inflection in Italian Dialects. In: Svenonius P. (Ed.), Subjects, Expletives and EPP. Oxford Univeristy Press, Oxford, pp. 157-199.

Marandin, J.-M. , Beyssade, C., Delais-Roussarie, E., Rialland, A., 2002. Discourse marking in French: $\mathrm{C}$ accents and discourse moves. In: Bel, B., Marlien, I. (Eds.), Proceedings SPEECH PROSODY 2002, Aix-en-Provence.

Mayol, L., 2002. 'Ho sabíeu, això?' la dislocació a la dreta en català i en angles. MA Thesis, Universitat Pompeu Fabra.

McNally, L., 1998. On the linguistic encoding of information packaging instructions. In: Culicover, P., McNally, L. (Eds.) The Limits of Syntax, Syntax and Semantics 29, Academic Press, New York, pp. 161-183.

Molnár, V. 2002. Contrast - from a contrastive perspective. In: Hallelgard, H., Johansson, S., Behrens, B., Fabricius-Hansen, C. (Eds.), Information Structure in a Cross-Linguistic Perspective. Rodopi, Amsterdam/New York, pp.147-161.

Murcia-Serra, J., 2003. Acquiring the linkage between syntactic, semantic and informational roles in narratives by Spanish learners of German. In: Dimroth, C., Starren, M. (Eds.) Information Structure and the Dynamics of Language Acquisition. John Benjamins, Philadelphia.

Neeleman, A., van de Koot, H., 2006. The Nature of Discourse Templates. Ms. University College London.

van Oosten, J., 1986. The Nature of Subjects, Topics and Agents: A Cognitive Explanation. Indiana University Linguistics Club.

Pierrehumbert, J.B., 1980. The phonology and phonetics of English intonation. $\mathrm{PhD}$ dissertation, Massachusetts Institute of Technology.

Poletto, C., 2000. The higher functional field: Evidence from northern Italian dialects. Oxford University Press, New York.

Prince, E., 1992. The ZPG letter: subjects, definiteness and information status. Discourse description: diverse linguistic analyses of a fund raising text. In: W. Mann, Thompson, S. (Ed.), Benjamins, Philadelphia, pp. 295-325.

Reinhart, T., 1981. Pragmatics and Linguistics: An Analysis of Sentence Topics. Philosophica, 27, pp. 53-94.

Rizzi, L., 1997. The fine structure of the left periphery. In: Haegeman, L. (ed.) Elements of Grammar: Handbook in Generative Syntax, Kluwer, Dordrecht, pp. 281-337. 
Rizzi, L., 2005. On some properties of subjects and topics. In Brugé, L., Giusti, G., Munaro, N., Schweikert, W., Turano, G. (Eds.). Proceedings of the XXX Incontro di Grammatica Generativa. Cafoscarina, Venice, Italy.

Rooth, M., 1992. A Theory of focus interpretation. Natural Language Semantics 1, pp. 75-116.

Salvi, G., 1988. La frase semplice. In Renzi, L., Salvi, G., Cardinaletti, A. (Eds.), vol. 1: Grande grammatica italiana di consultazione. Il Mulino, Bologna, pp.37-127.

Samek-Lodovici, V., 1996. Constraints on Subjects. An Optimality Theoretic Analysis. Ph.D. Dissertation, Rutgers University, New Brunswick, NJ.

Samek-Lodovici, V., 2006. When Right Dislocation Meets the Left-Periphery. A Unified Analysis of Italian Non-final Focus. Lingua 116, pp. 836-873.

Samek-Lodovici, V., forthcoming. Topic, Focus, and Background in Italian Clauses. In: Dufter, A., Jacob, D. (Eds.), Focus and Background in Romance Languages, John Benjamins, Amsterdam.

Schwarzschild, R., 1999. Giveness, Avoid-F and other constraints on the placement of accent. Natural Language Semantics 7, pp.141-177.

Skopeteas, S., Féry, C., 2006. Contrastive Topics in Pairing Answers: A CrossLinguistic Production Study. In: Featherston, S., Sternefeld, W. (Eds.), Linguistic Evidence, Mouton De Gruyter, Berlin.

Strawson, P., 1964. Identifying reference and truth-value. Theoria 30, pp. 96-118, reprinted in: Strawson, P. 1971. Logico-linguistic papers, Methuen, pp. 75-95.

Strömqvist, S., Verhoven, L.T. (Eds.), 2004. Relating events in narrative, Vol.2: Typological and contextual perspectives. Lawrence Erlbaum Associate, Mahwah, NJ.

Suñer, M., 2003. The Lexical Preverbal Subject in a Romance Null Subject Language: Where are Thou? In: Núñez-Cedeño, R., López, L., Cameron, R. (Eds.), A Romance Perspective on Language Knowledge and Use. Selected Papers from the 31st Linguistic Symposium on Romance Languages (LSRL), John Benjamins, Amsterdam, pp. 341-58.

Tancredi, C.D., 1992. Deletion, Deaccenting and Presupposition. PhD dissertation, Massachusetts Institute of Technology.

Turan, U.D. 1995. Subject and Object in Turkish Discourse: A Centering Analysis. PhD dissertation, University of Pennsylvania.

Vallduví, E., 1992. The Informational Component. Garland, New York.

Vallduví, E., 1993. Catalan as vos : Evidence from Information Packaging. In: Perissinotto, G., Sabih, W.J., Mithun, M., Raposo, E. (Eds.), Linguistic Perspectives on the Romance Languages, John Benjamins, Amsterdam/Philadelphia, pp. 335-350.

Vallduví, E., 1995. Structural properties of information packaging in Catalan. In: É.Kiss, K. (Ed.), Discourse configurational languages, Oxford University Press, Oxford, pp. 122-152.

Vallduví, E., Engdhal, E. 1996. The linguistic realization of information packaging. Linguistics 34.

Vallduví, E., Vilkuna, M. 1998. On rheme and contrast. In Culicover, P., McNally, L. (Eds.), Syntax and Semantics, 29: The limits of Syntax, Academic Press, New York.

Villalba, X., 1998. Right Dislocation is not right dislocation. In: Fullana, O., Roca, F. (Eds.), Studies on the Syntax of Central Romance Languages. Proceedings of 
the III Symposium on the Syntax of Central Romance Languages. Universitat de Girona, pp. 227-241.

Walker, M., Iida, M., Cote, S., 1994. Japanese Discourse and the Process of Centering. Computational Linguistics, 20/2, pp. 193-232.

Ward, G., Prince, E., 1991. On the topicalization of indefinite NPs. Journal of Pragmatics 15, 8, pp. 167-78.

Wedgwood, D., 2007. Identifying inferences in focus. In: Schwabe, K., Winkler, S. (Eds.), On Information Structure, Meaning and Form, John Benjamins, Amsterdam/Philadelphia.

Ziv, Y., Grosz, B., 1994. Right dislocation and attentional state. In: Buchalla, R., Mittwoch, A. (Eds.), Papers from the Israel Association of Theoretical Linguistics Meetings, Akademon Press, Jerusalem.

Zubizarreta, M.L., 1998. Topic, Focus and Word Order. MIT Press, Cambridge, MA. 